\title{
Monitoring of seasonal glacier mass balance over the European Alps using low-resolution optical satellite images
}

\author{
VANESSA DROLON, ${ }^{1}$ PHILIPPE MAISONGRANDE, ${ }^{1}$ ETIENNE BERTHIER, ${ }^{1}$ \\ ELSE SWINNEN, ${ }^{2}$ MATTHIAS HUSS ${ }^{3,4}$ \\ ${ }^{1}$ LEGOS, Université de Toulouse, CNRS, CNES, IRD, UPS, 14 av Edouard Belin, 31400 Toulouse, France \\ ${ }^{2}$ Remote Sensing Unit, Flemish Institute for Technological Research (VITO), Boeretang 200, 2400 MOL, Belgium \\ ${ }^{3}$ Department of Geosciences, University of Fribourg, Chemin du Musée 4, CH-1700 Fribourg, Switzerland \\ ${ }^{4}$ Laboratory of Hydraulics, Hydrology and Glaciology (VAW), ETH Zurich, Hönggerbergring 26, CH-8093 Zurich, \\ Switzerland \\ Correspondence: Vanessa Drolon <vanessa.drolon@legos.obs-mip.fr>
}

\begin{abstract}
We explore a new method to retrieve seasonal glacier mass balances (MBs) from lowresolution optical remote sensing. We derive annual winter and summer snow maps of the Alps during 1998-2014 using SPOT/VEGETATION $1 \mathrm{~km}$ resolution imagery. We combine these seasonal snow maps with a DEM to calculate a 'mean regional' altitude of snow $(Z)$ in a region surrounding a glacier. Then, we compare the interannual variation of $Z$ with the observed winter/summer glacier MB for 55 Alpine glaciers over 1998-2008, our calibration period. We find strong linear relationships in winter (mean $R^{2}=0.84$ ) and small errors for the reconstructed winter MB (mean RMSE $=158 \mathrm{~mm}\left(\right.$ w.e.) $\mathrm{a}^{-1}$ ). This is lower than errors generally assumed for the glaciological MB measurements (200-400 $\mathbf{m m}$ w.e. $\mathrm{a}^{-1}$ ). Results for summer MB are also satisfying (mean $R^{2}$ and RMSE, respectively, 0.74 and $314 \mathrm{~mm} \mathrm{w}$. e. $\mathrm{a}^{-1}$ ). Comparison with observed seasonal MB available over 2009-2014 (our evaluation period) for 19 glaciers in winter and 13 in summer shows good agreement in winter (RMSE $=405 \mathrm{~mm}$ w.e. $\mathrm{a}^{-1}$ ) and slightly larger errors in summer $\left(\right.$ RMSE $=561 \mathrm{~mm}$ w.e. $\mathrm{a}^{-1}$ ). These results indicate that our approach might be valuable for remotely determining the seasonal $\mathrm{MB}$ of glaciers over large regions.
\end{abstract}

KEYWORDS: Alps, glaciers mass balance, NDSI, snow, SPOT/VEGETATION

\section{INTRODUCTION}

Glacier mass balance (MB) is highly sensitive to atmospheric conditions and constitutes a direct and perceptible indicator of climate change (Haeberli and Beniston, 1998). On a global scale, the mass loss of glaciers (apart from the Greenland and Antarctica ice sheets) constitutes the major contribution to present sea-level rise (IPCC, 2013). For example, over the well-observed 2003-2009 period, glacier mass loss was $259 \pm 28 \mathrm{Gt} \mathrm{a}^{-1}$, representing about $30 \pm 13 \%$ of total sea-level rise (Gardner and others, 2013). Between 1902 and 2005, glacier mass loss, reconstructed by Marzeion and others (2015), corresponds to $63.2 \pm 7.9 \mathrm{~mm}$ sea-level equivalent (SLE). Glacier mass losses are projected to increase in the future and are expected to range between $155 \pm 41 \mathrm{~mm}$ SLE (for the emission scenario RCP4.5) and $216 \pm 44 \mathrm{~mm}$ SLE (for RCP8.5) between 2006 and 2100 (Radić and others, 2014). Moreover, on continental surfaces, glacier behaviour strongly determines watershed hydrology: glacier meltwater impacts on the runoff regime of mountainous drainage basins and consequently on the availability of the water resource for populations living downstream (Huss, 2011). Many scientific, economic and societal stakes are thus related to glaciers (Arnell, 2004; Kaser and others, 2010), hence justifying regular monitoring.

Traditionally, the annual and seasonal glacier MBs are measured using glaciological in situ measurements from repeated snow accumulation surveys and ice ablation stake readings on individual glaciers, that are subsequently extrapolated over the entire glacier area (Østrem and Brugman, 1991; Kaser and others, 2003). Nevertheless, this laborious technique requires heavy logistics, is time consuming and moreover is subject to potential systematic errors (e.g. Thibert and others, 2008). Glaciological MB measurements are thus limited to a few easily accessible glaciers, unequally distributed around the globe: only about 150 glaciers among the world's 200 000 glaciers are regularly monitored in the field and present at least ten consecutive years of $\mathrm{MB}$ measurements (Pfeffer and others, 2014; Zemp and others, 2015).

Several remote sensing techniques are used to increase data coverage of glacier mass change at a global scale. One of them is the geodetic method, which consists of monitoring glacier elevation changes by differencing multitemporal DEMs. These DEMs can be derived from aerial photos and/or airborne Light Detection and Ranging (LiDAR) (Soruco and others, 2009; Abermann and others, 2010; Jóhannesson and others, 2013; Zemp and others, 2013). However, the main limitation of airborne sensors is their geographic coverage, restricted to areas accessible with airplanes; some large remote areas such as High Mountain Asia can hardly be monitored. LiDAR data from the Ice Cloud and Elevation Satellite (ICESat) altimeter can also provide information on glacier elevation changes, but these data are too sparse to allow reliable monitoring of the mass budget of individual glaciers (Kropáček and others, 2014; Kääb and others, 2015). DEMs can also be derived from medium-to-high resolution optical satellite images such as Satellite pour l'Observation de la Terre-High Resolution Stereoscopic (SPOT5/HRS) images or radar satellite images as done during the Shuttle Radar Topographic Mission (SRTM). However, the vertical precision of these 
DEMs $(\sim 5 \mathrm{~m})$ is such that it remains challenging to accurately estimate the MB of individual small to medium-sized glaciers (glaciers $<10 \mathrm{~km}^{2}$ ) (Paul and others, 2011; Gardelle and others, 2013). More recently, Worldview and Pléiades submeter stereo images have been used to provide accurate glacier topography with a vertical precision of $\pm 1 \mathrm{~m}$ and even $\pm 0.5 \mathrm{~m}$ on gently sloping glacier tongues (Berthier and others, 2014; Willis and others, 2015). Nevertheless, repeatedly covering all glaciers on Earth with Worldview and Pléiades stereo images would be very expensive given their limited footprint for a single scene (e.g. $20 \mathrm{~km} \times 20 \mathrm{~km}$ for Pléiades). Due to DEM errors and uncertainties in the density value for the conversion from volume change to mass change (Huss, 2013), this method currently provides $\mathrm{MB}$ at a temporal resolution typically, of 5-10 a. This does not provide an understanding of glacier response to climatic variations at seasonal and annual timescales (Ohmura, 2011).

An alternative method to estimate the MB change of a glacier is based on the fluctuations of the glacier equilibrium line altitude (ELA) (Braithwaite, 1984; Kuhn, 1989; Leonard and Fountain, 2003; Rabatel and others, 2005). The ELA is the altitude on a glacier that separates its accumulation zone, where the annual $M B$ is positive, from its ablation zone, where the annual MB is negative (Ohmura, 2011; Rabatel and others, 2012). The ELA and annual glacierwide $\mathrm{MB}$ are strongly correlated. Early studies have shown that the ELA can be efficiently approximated by the snowline altitude at the end of the ablation season (i.e. at the end of the hydrological year) on mid-latitude glaciers (LaChapelle, 1962; Lliboutry, 1965). The snowline altitude measured at the end of the ablation season thus constitutes a proxy for estimating the annual MB. This method has been applied to glaciers located in the Himalayas, Alaska, Western North America, Patagonia and the European Alps amongst others, using aerial photographs or optical remote sensing images from Landsat and MODIS (Ostrem, 1973; Mernild and others, 2013; Rabatel and others, 2013; Shea and others, 2013). However, the Landsat temporal resolution of $16 \mathrm{~d}$ can be a strong limitation for accurately studying the dynamics of snow depletion, especially in mountainous regions with widespread cloud coverage (Shea and others, 2013); and the methodologies used with MODIS (available since 2000) to detect ELA often require complex algorithms implying heavy classification (Pelto, 2011; Shea and others, 2012; Rabatel and others, 2013).

Unlike the above-mentioned techniques, only a few recent studies have focused on retrieving seasonal glacier MBs (Hulth and others, 2013; Huss and others, 2013). Seasons are in fact, more relevant timescales to better understand the glacier response to climate fluctuations, allowing the partitioning of recent glacier mass loss between changes in accumulation (occurring mainly in winter) and changes in ablation (occurring mainly in summer), at least in the mid- and polar latitudes (Ohmura, 2011). Hulth and others (2013) combined melt modelling using meteorological data and snowline tracking measured in the field with GPS to determine winter glacier snow accumulation along snowlines. Huss and others (2013) calculated the evolution of glacier-wide MB throughout the ablation period also by combining simple accumulation and melt modelling with the fraction of snow-covered surface mapped from repeated oblique photography. Both methods have been applied for only one or two glaciers, and a few years as they are time- consuming and require various datasets (meteorological data, remotely sensed data) that are not widely available.

In this context, the consistent archive of optical SPOT/ VEGETATION (SPOT/NGT) images, spanning 1998-2014 with a daily and nearly global coverage at $1 \mathrm{~km}$ resolution (Sylvander and others, 2000; Maisongrande and others, 2004; Deronde and others, 2014), remains an unexploited dataset to estimate the year-to-year seasonal MB variations of glaciers. Instead of detecting the exact physical snowline altitude of a glacier as done in earlier studies, our new method focuses on monitoring a 'mean regional' seasonal altitude of snow $(Z)$, in a region surrounding a glacier, during summer (from early May to the end of September) and winter (from early October to the end of April). The interannual dynamics of this altitude $Z$, estimated from SPOT/ VGT images, is then compared with the interannual variation of observed seasonal MBs (derived from direct glaciological measurements), available continuously every year over 1998-2008, for 55 glaciers in the Alps (WGMS, 2008, 2012, 2013; Huss and others, 2010a, b, 2015). The performance of the 55 individual linear regressions between $Z$ and $M B$ are analysed in terms of the linear determination coefficient $R^{2}$ and the RMSE. For each of the 55 regressions, we then perform a cross-validation of the temporal robustness and skill of the regression coefficients. For all 55 glaciers, seasonal MBs are then calculated outside of the calibration period, i.e. each year of the 2009-2014 interval. A validation is realized for some glaciers with observed seasonal MB over 2009-2014. Finally, we discuss the possible causes of differences in the results between seasons, between glaciers and present the limits and perspectives of our methodology.

\section{DATA}

\subsection{Satellite data}

This study uses optical SPOT/VGT satellite images provided by two instruments: VEGETATION 1 from April 1998 to the end of January 2003 (VGT 1 aboard the SPOT 4 satellite launched in March 1998), and VEGETATION 2 from February 2003 to the end of May 2014 (VGT 2 aboard the SPOT 5 satellite launched in May 2002). The instruments provide a long-term dataset (16 a) with accurate calibration and positioning, continuity and temporal consistency. The SPOT/VGT sensors have four spectral bands: the blue B0 $(0.43-0.47 \mu \mathrm{m})$, the red B2 $(0.61-0.68 \mu \mathrm{m})$, the Near InfraRed B3 $(0.78-089 \mu \mathrm{m})$ and the Short Wave Infra-Red SWIR $(1.58-1.75 \mu \mathrm{m})$. Both sensors provide daily images of almost the entire global land surface with a spatial resolution of $1 \mathrm{~km}$, in a 'plate carree' projection and a WGS84 datum (Deronde and others, 2014). In this study, we used the SPOTNGT-S10 products (10-daily syntheses) freely available between April 1998 and May 2014 (http://www.vitoeodata.be/PDF/portal/Application.html\#Home). The SPOT/ VGT-S10 products, processed by Vlaamse Instelling voor Technologisch Onderzoek (VITO), result from the merging of data strips from ten consecutive days (three 10-d syntheses are made per month) through a classical Maximum Value Composite (MVC) criterion (Tarpley and others, 1984; Holben, 1986). The MVC technique consists of a pixel-bypixel comparison between the 10-daily Normalized Difference Vegetation Index (NDVI) images. For each pixel, the maximum NDVI value at top-of-atmosphere is picked. This selection allows minimizing cloud cover and aerosol 
contamination. Due to atmospheric effects, an atmospheric correction is applied to the VGT-S10 products (Duchemin and Maisongrande, 2002; Maisongrande and others, 2004) based on a modified version of the SMAC (Simple Method for the Atmospheric effects) code (Rahman and Dedieu, 1994). The SPOT/VGT-S10 Blue, Red and SWIR spectral bands have been gathered from 1 April 1998 to 31 May 2014, over a region including the Alps and stretching from 43 to $48.5^{\circ} \mathrm{N}$ and from 4 to $17^{\circ} \mathrm{E}$ (Fig. 1).

The terrain elevation over the studied region has been extracted from the SRTM30 DEM, derived from a combination of data from the SRTM DEM (acquired in February 2000) and the U.S. Geological Survey's GTOPO30 dataset (Farr and Kobrick, 2000; Werner, 2001; Rabus and others, 2003). The SRTM30 spatial resolution is $30 \operatorname{arcsec}(\sim 900 \mathrm{~m})$ and the geodetic reference is the WGS84 EGM96 geoid. The DEM has been resampled using the nearest-neighbour method to a $1 \mathrm{~km}$ spatial resolution in order to match the resolution of the S10 SPOT/VGT images.

\subsection{Glacier MB data}

Glacier-wide winter and summer MB data of 55 different glaciers are used in this study (Table S1 in the Supplementary Material; Fig. 1), covering a total area of $\sim 400 \mathrm{~km}^{2}$, corresponding to $19 \%$ of the $2063 \mathrm{~km}^{2}$ glacier area in the Alps (Pfeffer and others, 2014). Winter MB $\left(B_{\mathrm{w}}\right)$ is measured through to the end of April. Summer $M B\left(B_{\mathrm{s}}\right)$ is the difference between annual $\mathrm{MB}$ determined at the end of the ablation period (end of September) and winter MB (Thibert and others, 2013). Winter MB corresponds to the snow/ice mass accumulated during the winter season (from

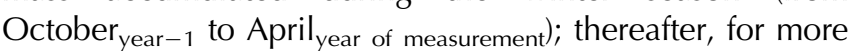
clarity, $B_{\mathrm{w} \text { obs }}$ refers to the winter $\mathrm{MB}$ measured in April of the year of measurement and $B_{\mathrm{s}_{\_} \text {obs }}$ to the summer MB measured in September of the year of measurement.

The different MB datasets all start before 1998. However, as we later compare these MB data with SPOT/VGT snow maps available since April 1998, we used seasonal MB only after 1998.

The first MB dataset is composed of direct glaciological measurements provided by the World Glacier Monitoring Service (WGMS, 2013). Seasonal MB of 44 Austrian, French, Italian and Swiss glaciers of the European Alps are available between 1950 and 2012 (for the longest series) but with discontinuous data. At the time of access to the database, continuous seasonal MB time series were only available for seven glaciers since 1998 (labelled 'source 1' in Table S1).

The second $\mathrm{MB}$ dataset provided by Huss and others (2015) is derived from recently re-evaluated glaciological measurements. For seven Swiss glaciers (labelled 'source 2' in Table S1), long-term continuous seasonal MB series from 1966 (at least) to 2014 are inferred from point measurements extrapolated to the entire glacier using distributed modelling, with year-to-year variability directly given by the in situ measurements.

The third MB dataset, composed of 41 Swiss glaciers, is a comprehensive set of field data homogenized using distributed modelling, with year-to-year variation constrained by meteorological data (Huss and others, 2010a, b). The seasonal MB time series of 21 glaciers covering $30 \%$ of the total glacier area of Switzerland (labelled 'source $3 \mathrm{a}^{\prime}$ in Table S1), are available for each year of the 1908-2008 period (Huss and others, 2010a). For 20 other glaciers located in the southeastern Swiss Alps (labelled 'source $3 b^{\prime}$ in Table S1), seasonal MB time series are provided each year from 1900 to 2008 (Huss and others, 2010b). The continuous seasonal MB series of these 41 glaciers are derived from three different data sources:

(1) Geodetic data of volume change for periods of four to $\sim 40$ a; three to nine DEMs have been used for each glacier since 1930, mostly originating from aerial photogrammetry or terrestrial topographic surveys for the first DEM.

(2) (Partly isolated) in situ measurements of accumulation and ablation for about half of the glaciers; they were used to constrain $\mathrm{MB}$ gradients and winter accumulation.

(3) Distributed accumulation and temperature-index melt modelling (Hock, 1999; Huss and others, 2008) forced with meteorological data of daily mean air temperature and precipitation, recorded at various weather stations close to each of the glaciers. The model is constrained by ice volume changes obtained from DEM differencing and calibrated with in situ measurements when available. Huss and others (2008) provide more details on the model and calibration procedure.

In order to have the most complete set of continuous interannual MB data to calibrate our method, we chose to
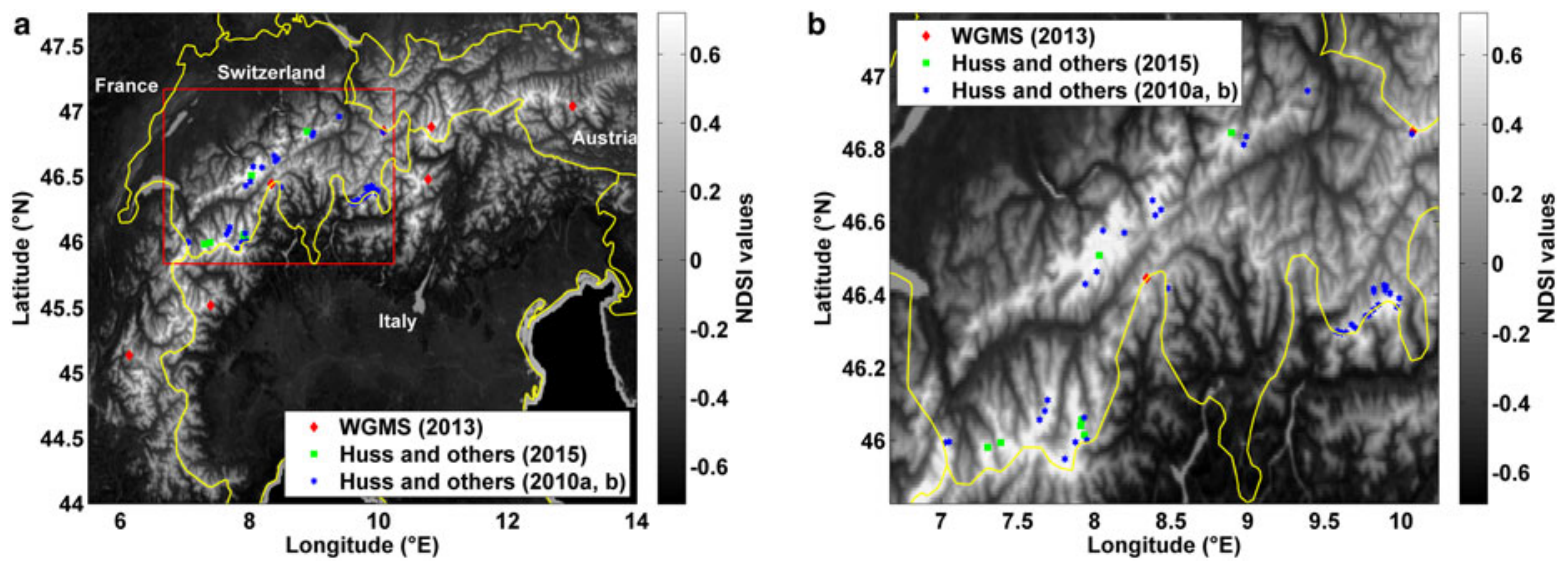

Fig. 1. Map of the mean NDSI for the period 1998-2014, over the European Alps, and location of the studied glaciers with MB balance measurements (sources 1-3; Table S1). (a) Entire study area. (b) Enlargement of the studied area (red rectangle in (a)). 
combine MB time series from all sources $(1,2,3 a$, b) over the same period. Since 41 glaciers (annotated $3 a, b$ in Table S1) provide continuous seasonal MB until 2008, the calibration period extends until 2008. As we later compare MB data with SPOT/VGT images provided since April 1998, 19992008 constitutes the winter calibration period and 19982008 the summer calibration period. In total, 55 glaciers with 10 a of winter MB ( $\left.B_{\mathrm{w}_{-} \text {obs }}\right)$ over 1999-2008, and 11 a of summer $\mathrm{MB}$ ( $B_{\mathrm{s} \_ \text {obs }}$ ) over 1998-2008 have thus been used to calibrate our approach. Coordinates, median elevation and glacier area are available for all 55 glaciers (Table S1).

Furthermore, seasonal MBs are also available for some of these 55 glaciers outside the calibration period (2009-2014, i.e. the end of the period covered by SPOT/VGT data). In winter, 66 additional $B_{\mathrm{w}-o b s}$ data are available in total for 19 glaciers over 2009-2014 and in summer, $49 B_{\text {s obs }}$ measurements are available for 13 glaciers over 2009-2013 (summer 2014 is not covered by SPOT/NGT) (WGMS, 2013; Huss and others, 2015).

Errors associated with $B_{\mathrm{w}-\mathrm{obs}}$ and $B_{\mathrm{s} \_ \text {obs }}$ are not provided individually per glacier. Zemp and others (2013) find an average annual random error of $340 \mathrm{~mm}$ w.e. $\mathrm{a}^{-1}$ for 12 glaciers with long-term MB measurements. Huss and others (2010a) have quantified the uncertainty in glacier-wide winter balance (see Supplementary Information in their paper) as $\pm 250 \mathrm{~mm}$ w.e. $\mathrm{a}^{-1}$. This number is not directly applicable to all glaciers (depending on the sampling), but to most of them. Systematic errors associated with in situ glaciological MBs are expected to be within $90-280 \mathrm{~mm}$ w.e. $\mathrm{a}^{-1}$ if cautious measurements are realized with sufficient stake density (Dyurgerov and Meier, 2002), but they are generally assumed to range between 200 and $400 \mathrm{~mm}$ w.e. $\mathrm{a}^{-1}$ for one glacier (Braithwaite and others, 1998; Cogley and Adams, 1998; Cox and March, 2004). In this study, we consider an error (noted $E_{\text {obs }}$ ) of $\pm 200-400 \mathrm{~mm}$ w.e. $\mathrm{a}^{-1}$ for observed MB.

\section{METHODS}

\subsection{Cloud filtering and temporal interpolation of the snow cover maps}

Snow discrimination is based on its spectral signature, which is characterized by a high reflectance in the visible and a high absorption in the SWIR wavelength. Consequently, the Normalized Difference Snow Index (NDSI) first introduced by Crane and Anderson (1984) and Dozier (1989) for the Landsat sensor, defined as a band ratio combining the visible (green) and SWIR Landsat bands, constitutes a good and efficient proxy to map the snow cover with optical remote sensing. The NDSI has since been widely used with different sensors (e.g. Fortin and others, 2001; Hall and others, 2002; Salomonson and Appel, 2004). The NDSI value is proportional to the snow cover rate of the pixel and allows a monitoring of the spatial and temporal snow cover variations (Chaponnière and others, 2005). In this study, we build an NDSI adapted to the SPOT/NGT sensor (without green channel), inspired by Chaponnière and others (2005). This modified NDSI is computed from the mean of the red B0 and blue B2 channels (to recreate an artificial green band) and from the SWIR:

$$
N D S I=\frac{(B 0+B 2) / 2-S W I R}{(B 0+B 2) / 2+S W I R} .
$$

A different (and more standard) formulation of the NDSI is used for the MODIS sensor and calculated only with the red B0 channel and the SWIR (Xiao and others, 2001). Our entire methodology was also tested with this standard NDSI but led to results of inferior quality (not shown).

Clouds have a spectral signature similar to snow and they can be misclassified as snow, especially at the edge of the snow pack. We apply a cloud mask proposed by Dubertret, (2012) (and refer to as D-12 cloud mask below) in order to flag cloudy pixels and to avoid overestimating snow coverage. This algorithm, based on various reflectance bands threshold tests, has been adapted to SPOT/VGT images from different cloud masks initially created for higher resolution imagery. It corresponds to the crossing of Sirguey's cloud mask (developed for MODIS sensor) (Sirguey and others, 2009) and of Irish and Zhu's cloud masks, both developed for the Landsat sensor (Irish, 2000; Zhu and Woodcock, 2012). When compared with other classical cloud detection algorithms (e.g. Berthelot, 2004), the D-12 cloud mask performs the best cloud identification, along with Lissens and others (2000) cloud mask. However, Dubertret (2012) concluded that the D-12 cloud mask is more conservative than that of Lissens and others (2000) and allows detection of more-snow covered pixels (by flagging less clouds). We therefore choose to apply the cross-cloud mask on the S10 syntheses, which are composites of the S1 daily images pixels over $10 \mathrm{~d}$.

A temporal interpolation is then computed for the 'cloudy' pixels when possible. If a pixel is detected as cloudy in a S10 synthesis, its value is replaced by the mean of the same pixel value in the previous synthesis $\left(\mathrm{S}_{\mathrm{O}} \mathrm{O}_{t-1}\right)$, and in the next one $\left(\mathrm{S}_{10} \mathrm{O}_{t+1}\right)$ if these pixels are not cloudy. If they are, we compute the mean of the $\mathrm{S}_{10} \mathrm{O}_{t-2}$ and the $\mathrm{S}_{10} \mathrm{O}_{t+2}$ synthesis pixel values. In order to produce maps of winter/summer NDSI, we average all 10-d NDSI syntheses included between 1 October and 30 April for each winter of the 1999-2014 period, and between 1 of May and 30 of September for each summer of the 1998-2013 period.

\subsection{Calibration}

We first superimpose each interannual mean seasonal NDSI map derived from SPOT/VGT for the period 1998-2014 on the SRTM30 DEM. Then, considering different sized of square windows varying from 5 to $401 \mathrm{~km}$ side lengths (with steps of $2 \mathrm{~km}$ ) of $\mathrm{P} \times \mathrm{P}$ pixels and centred on each glacier, we derive the altitudinal distribution of the mean seasonal NDSI. For each glacier, we thus obtain the interannual dynamics of the NDSI altitudinal distribution within different Windows of Snow Monitoring (WOSM) sizes surrounding the glacier (16 curves; Fig. 2). The WOSM side lengths tested are always odd numbers for the glacier to be situated in the central pixel of the square window. Then for each WOSM size, from the intersection between a NDSI value (varying from 0.2 to 0.65 , with a step of 0.01 ) and each seasonal curve of the NDSI altitudinal distribution, a 'mean regional' altitude of snow ( $Z$ ) can be deduced each year, from 1998 to 2014. We do not focus on detecting the exact physical snowline elevation of the glacier at the end of the melt season to estimate annual $\mathrm{MB}$, as done in previous studies (e.g. Rabatel and others, 2005). In fact, the SPOT/ VGT $1-\mathrm{km}$ resolution is not adapted to monitor the snowline elevation and its high spatial variability. Moreover, the snowline approach does not allow us to retrieve seasonal $M B$, 

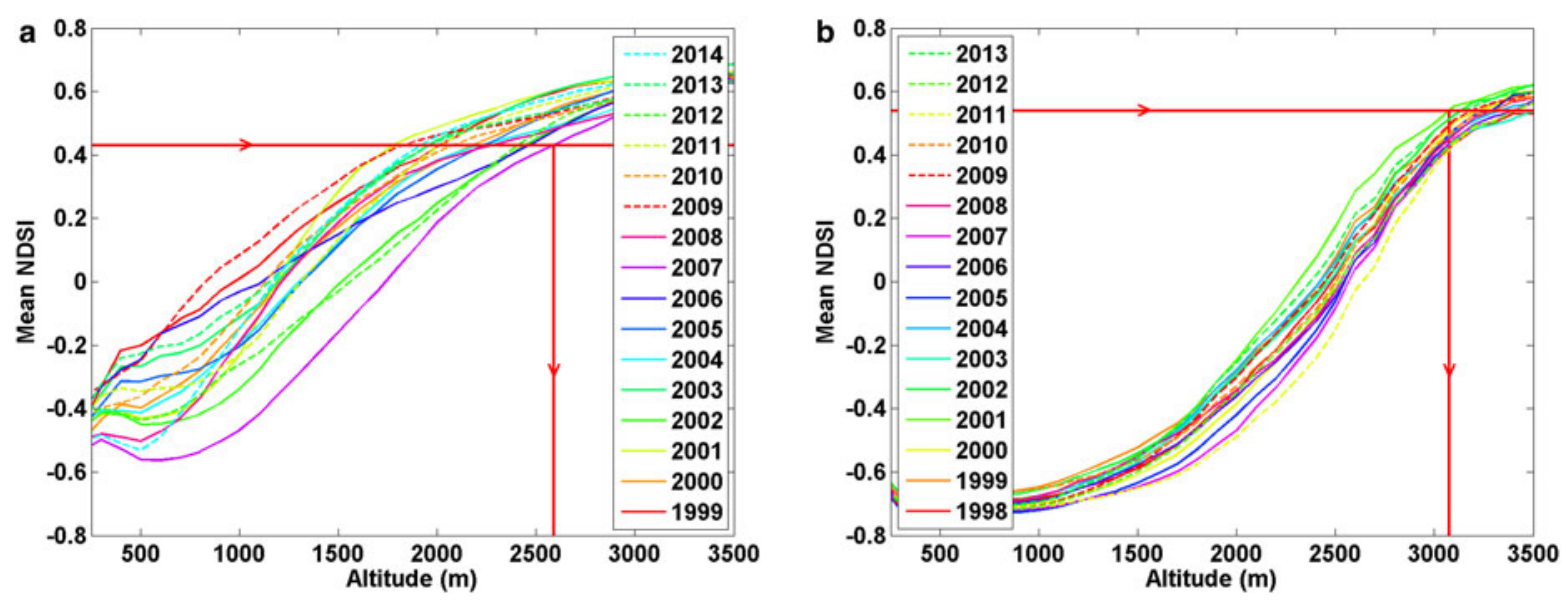

Fig. 2. Altitudinal distribution of NDSI for each year since 1998. The NDSI has been averaged in a square window centred on Griesgletscher, central Swiss Alps. The red horizontal line represents the NDSI value from which the mean regional snow altitude $Z$ (represented by the red vertical line) is inferred for each year. (a) Winter NDSI over 1999-2014 (WOSM size: $367 \times 367$ km²; NDSI value: 0.43). (b) Summer NDSI over 1998-2014 (WOSM size: $117 \times 117 \mathrm{~km}^{2}$; NDSI value: 0.54$)$.

because at the end of the accumulation period (end of April/ beginning of May in the Alps), the entire glacier is generally covered by snow. For these reasons, we aim at estimating for winter and for summer a statistical mean regional altitude of snow in a region surrounding a glacier. Finally, for each WOSM size and each NDSI value that are tested, we compute a linear regression between the mean regional snow altitudes $Z$ and the observed MBs (Fig. 3), over the calibration period (1999-2008 for winter, 1998-2008 for summer). This linear regression allows an interannual estimation of the glacier's seasonal MB, as a function of $Z$ inferred from SPOT/NGT, as written in the linear equation (generalized for both seasons):

$$
B_{\mathrm{w} / \mathrm{s}_{-} \mathrm{VGT}}=\alpha_{\mathrm{w} / \mathrm{s}} \times Z_{\mathrm{w} / \mathrm{s}}+\beta_{\mathrm{w} / \mathrm{s}} .
$$

$B_{\mathrm{w} / \mathrm{s}_{-} \text {VGT }}$ is the winter/summer MB estimated for the year $y$. $Z_{w / s}$ is the winter/summer 'mean regional' altitude of snow; the slope coefficient $\alpha_{\mathrm{w} / \mathrm{s}}$ expressed in $\mathrm{mm}$ w.e. $\mathrm{a}^{-1} \mathrm{~m}^{-1}$ represents the sensitivity of a glacier winter/summer $\mathrm{MB}$ towards $Z_{\mathrm{w} / \mathrm{s}}$ and $\beta_{\mathrm{w} / \mathrm{s}}$ is the winter/summer intercept term expressed in $\mathrm{mm}$ w.e. $\mathrm{a}^{-1}$.

Coefficients of determination $R_{\mathrm{w} / \mathrm{s}}^{2}$ and $R M S E_{\mathrm{w} / \mathrm{s}_{\text {_cal }}}$ are computed to assess the quality of the regression over the calibration period for each season.
To summarize, for each glacier, a linear regression is computed for each plausible NDSI value and all WOSM sizes. Following some initial tests on a subset of the 55 glaciers, the interval of plausible NDSI values is set to [0.2-0.65]. This NDSI range has also been chosen to include the reference NDSI value of 0.4 commonly accepted to classify a pixel as snow-covered (and associated with a pixel snow cover rate of 50\%) (Hall and others, 1995, 1998; Salomonson and Appel, 2004; Hall and Riggs, 2007; Sirguey and others, 2009). Then, for each glacier, and each size of WOSM tested, the seasonal NDSI value optimizing the $R M S E_{\mathrm{w} / \mathrm{s}_{\text {_cal }}}$ is selected. This NDSI value adjustment for each individual site (and each season) allows a better adaptation to the glacier-specific environment (e.g. local land cover type, local topography, etc.).

After adjusting the NDSI value, the size of the $\mathrm{P} \times \mathrm{P}$ pixels WOSM surrounding each glacier is also adjusted for each glacier and each season. Here again, the WOSM size minimizing the mean $R M S E_{\mathrm{w} / \mathrm{s}_{-} \text {cal }}$ is selected (Table $\mathrm{S} 1$ in Supplementary Material). The WOSM side lengths tested are always odd numbers for the glacier to be situated in the central pixel of the window. A mandatory condition for the WOSM size selection is the continuity of the NDSI altitudinal curves, given the $100 \mathrm{~m}$ altitudinal step. The cost function $f$
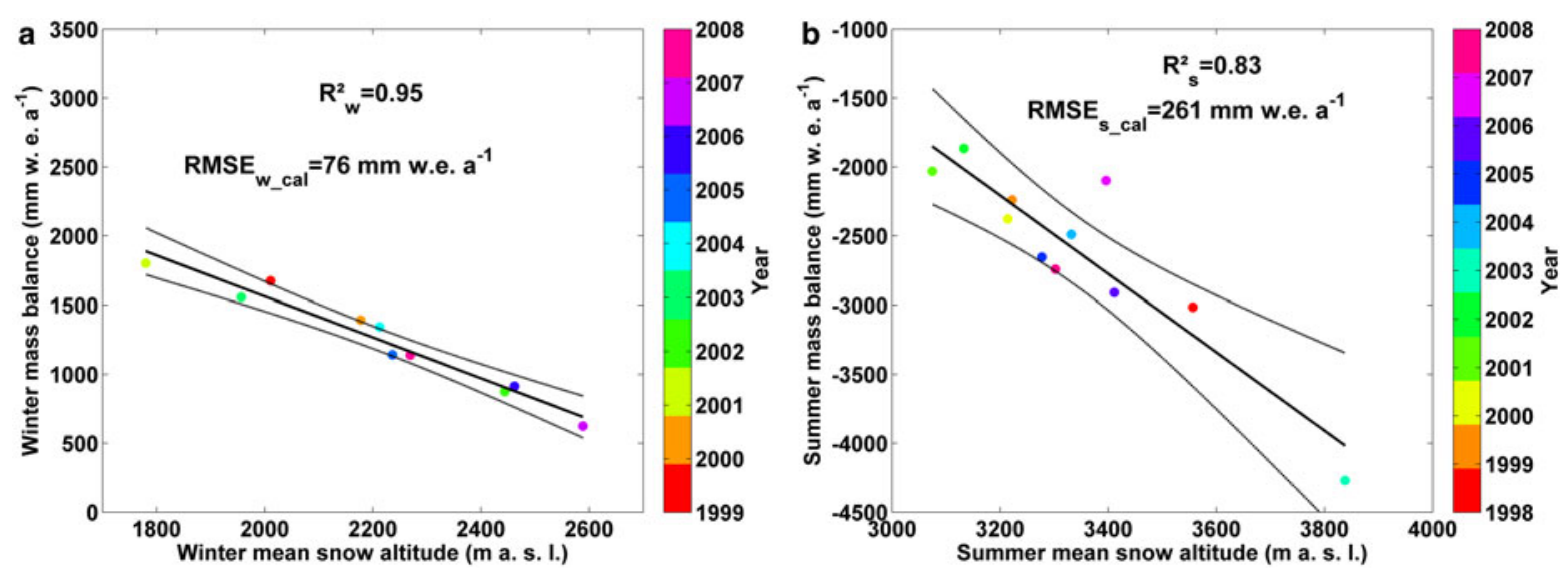

Fig. 3. Observed (a) winter and (b) summer MB of Griesgletscher, central Swiss Alps, as a function of the mean regional snow altitude $Z$ for each year of the calibration period represented by coloured dots. Dashed thin lines represent the $95 \%$ confidence intervals for linear regression (solid line). 
optimizing the $R M S E_{\mathrm{w} / \mathrm{s}_{-} \text {cal }}$ for each glacier is thus:

$$
\begin{aligned}
& f\left(N_{D S I^{*}}, \text { WOSM }^{*}, \alpha_{\mathrm{w} / \mathrm{s}}, \beta_{\mathrm{w} / \mathrm{s}}\right)= \\
& \quad \min \left(\sqrt{\frac{\sum_{y=1}^{N}\left(B_{\mathrm{w} / \mathrm{s} \_ \text {VGT } \mathrm{y}}-B_{\mathrm{w} / \mathrm{s} \_ \text {ref } y}\right)^{2}}{N}}\right) .
\end{aligned}
$$

NDSI* and WOSM* are respectively the NDSI value and the

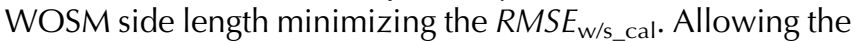
adjustment of both the NDSI value and the WOSM size is a means to select an optimized quantity of snow-covered pixels (where snow dynamics occurs) that are less affected by artefacts such as residual clouds, aerosols and/or directional effects. Changing NDSI value is a means to scan the terrain in altitude, while changing the windows size is a means to scan the terrain in planimetry.

Consequently, for each glacier, a unique 'optimized' linear regression (regarding the parameters $\alpha$ and $\beta$ ) allows us to estimate the seasonal $\mathrm{MB}$ from the mean regional snow altitude deduced with SPOT/VGT images.

\subsection{Validation}

To validate our results, we performed two types of evaluation: (1) cross-validation over the period 1998/1999-2008 and (2) evaluation against recent glaciological MB measurements (not used in the calibration) over the period 20092013/2014.

\subsubsection{Period 1998/1999-2008}

In order to validate the 55 individual optimized linear regressions, we use a classical leave-one-out cross-validation method based on the reconstruction of $M B$ time series where each $\mathrm{MB}$ value estimated for the year $y$ is independent of the observed MB for the same year $y$ (Michaelsen, 1987; Hofer and others, 2010; Marzeion and others, 2012). The cross-validation constitutes an efficient validation mechanism for short time series. For each glacier, we first determine the decorrelation time lag $t_{\text {lag }}(\mathrm{a})$, after which the autocorrelation function of the observed MB drops below the $90 \%$ significance interval, i.e. for which the serial correlation in the observed $\mathrm{MB}$ data is close to zero (for each glacier, $\left.t_{\text {lag }}=1\right)$. After that, for each glacier with $N$ available observed $\mathrm{MBs}(N=10$ in winter and $N=11$ in summer) we perform $N$ linear regressions between the regional mean snow altitude $Z_{\mathrm{w} / \mathrm{s}}$ and the observed $\mathrm{MB} B_{\mathrm{w} / \mathrm{s} \text { _obs }}$ leaving each time a moving window of $1 \mathrm{a} \pm t_{\mathrm{lag}}$ (i.e. $3 \mathrm{a}$ ) out of the data used for the regression. The removed value $\left(Z_{\mathrm{w} / \mathrm{s}, y}\right.$ and $\left.B_{\left.\mathrm{w} / \mathrm{s}_{\text {_obs, } y}\right)}\right)$ for the year $y$ has to be at the centre of the moving window such that the remaining values used for the regression are independent of the removed value. We then obtain $N$ values for the regression coefficients $\alpha$ and $\beta$ (termed $\alpha_{\mathrm{w} / \text { s_cross }}$ and $\beta_{\mathrm{w} / \text { s_cross }}$ ) and $N$ values of reconstructed $\mathrm{MB}\left(B_{\mathrm{w} / \mathrm{s}_{-} \mathrm{VGT} \text { _cross }}\right)$. Standard deviation of the $N$ regression coefficients $\sigma\left(\alpha_{\mathrm{w} / \mathrm{s} \_ \text {cross }}\right)$ and $\sigma\left(\beta_{\mathrm{w} / \mathrm{s} \text { _cross }}\right)$ are computed to assess the temporal stability and the robustness of the parameters $\alpha_{\mathrm{w} / \mathrm{s}}$ and $\beta_{\mathrm{w} / \mathrm{s}}$. The mean regression coefficients $\alpha_{\mathrm{w} / \mathrm{s} \_ \text {cross_best }}$ and $\beta_{\mathrm{w} / \text { s_cross_best }}$ representing the average of the $N \alpha_{\mathrm{w} / \mathrm{s} \text { _cross,y }}$ and $\beta_{\mathrm{w} / \mathrm{s} \text { _cross,y }}$ are also calcu-

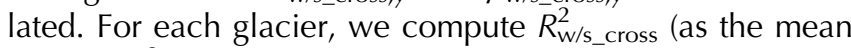
of the $N R_{\mathrm{w} / \mathrm{s}_{-}}^{2}$ obtained for the $N$ regressions) and an estimate of the error $R M S E_{\mathrm{w} / \mathrm{s} \_ \text {cross }}$ defined as:

$$
R M S E_{\mathrm{w} / \mathrm{s}_{\text {_cross }}}=\left(\sqrt{\frac{\sum_{y=1}^{N}\left(B_{\mathrm{w} / \mathrm{s}_{-} \mathrm{VGT}_{-} \text {cross }, y}-B_{\mathrm{w} / \mathrm{s}_{-} \mathrm{obs}, y}\right)^{2}}{N}}\right) .
$$

We then estimate the skill score of the linear regression as

$$
S S_{\mathrm{w} / \mathrm{s}}=1-\frac{R M S E_{\mathrm{w} / \mathrm{s}_{2} \text { cross }}^{2}}{R M S E_{\mathrm{w} / \mathrm{s} \_r e f \_c r o s s}^{2}},
$$

where $R M S E_{\mathrm{w} / \mathrm{s} \text { _obs_cross }}$ is the mean square error of a reference model. As the reference model, we determine $B_{\mathrm{w} / \mathrm{s}_{-} \text {ref_cross,y }}$ for each year $y$ by averaging the observed $\mathrm{MB}$ values leaving out $B_{\mathrm{w} / \mathrm{s}_{-} \text {obs, } y \text {, }}$ (allowing that $B_{\mathrm{w} / \mathrm{s}_{-} \text {ref_cross, } y}$ is independent of the observed $B_{\mathrm{w} / \mathrm{s} \text { oobs,y } y}$. The skill score can be interpreted as a parameter that measures the correlation between reconstructed and observed values, with penalties for bias and under (over) estimation of the variance (Wilks, 2011; Marzeion and others, 2012). A negative skill score means that the relationship computed has no skill over the reference model to estimate the seasonal MB.

\subsubsection{Period 2009-2013/2014}

As the period covered by SPOT/VGT data stretches until June 2014 , it is possible to calculate the seasonal MB after 2008 outside our calibration period for each glacier. From the intersection between the optimized NDSI value fixed for each glacier and the altitudinal distribution of the NDSI, we deduce a value of seasonal mean regional snow altitude for each year during 2009-2014 in winter and during 2009-2013 in summer. Therefore, with the individual 'optimized' relations computed over the calibration period, seasonal MB inferred from SPOT/VGT can be estimated over 2009-2013/2014. In winter, 66 additional $B_{\mathrm{w} \_ \text {obs }}$ data are available for 19 glaciers over 2009-2014 and in summer, $49 B_{\text {s_obs }}$ measurements are available for 13 glaciers over 2009-2013. Therefore, the annual and global RMSE $\left(R M S E_{\mathrm{w} / \mathrm{s}_{-} \text {eval }}\right)$ and Mass Balance Error $\left(\mathrm{MBE}_{\mathrm{w} / \mathrm{s} \_ \text {eval }}\right)$ can be calculated over each evaluation period.

\section{RESULTS}

\subsection{Performance over the calibration period 1998/ 1999-2008}

We analysed the performance of the linear regression model for the entire glacier dataset during winter and summer. The analysis was first performed individually for each glacier before considering the average results of the 55 glaciers.

\subsubsection{Individual glaciers}

Figure 4 presents individual performances for the 55 glaciers ranked by increasing RMSE over the calibration period. In winter, correlations between $Z_{\mathrm{w}}$ and $B_{\mathrm{w} \text {-obs }}$ are high (Fig. 4a): the mean $R_{\mathrm{w}}^{2}$ for the 55 glaciers is 0.84 . $R_{\mathrm{w}}^{2}$ ranges between 0.31 (for Aletsch, \#54 in Table S1) and 0.97 (for Seewjinen \#4), with high first quartile (0.79) and median values (0.88). Except for Aletsch, all $R_{\mathrm{w}}^{2}$ are superior to 0.5. Glaciers from source 3 result in higher mean $R_{w}^{2}(0.88)$ than glaciers from source $1(0.76)$ and 2 (0.72). Furthermore, the mean $R M S E_{\mathrm{w}_{-} \text {cal }}$ of the estimated $B_{\mathrm{w}_{-} V G T}$ for the 55 glaciers 
$\mathbf{R}^{2}$
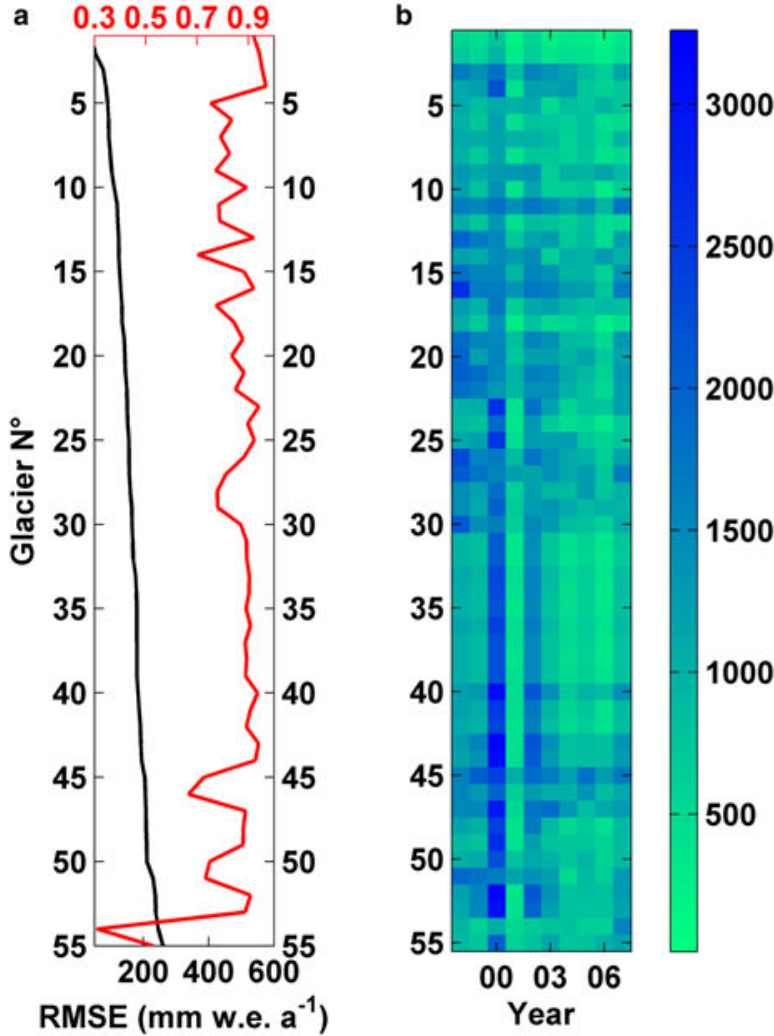

$\mathrm{R}^{2}$

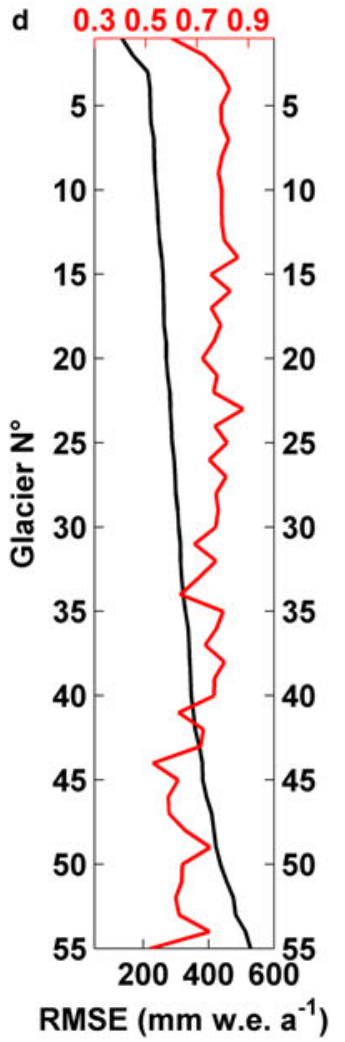

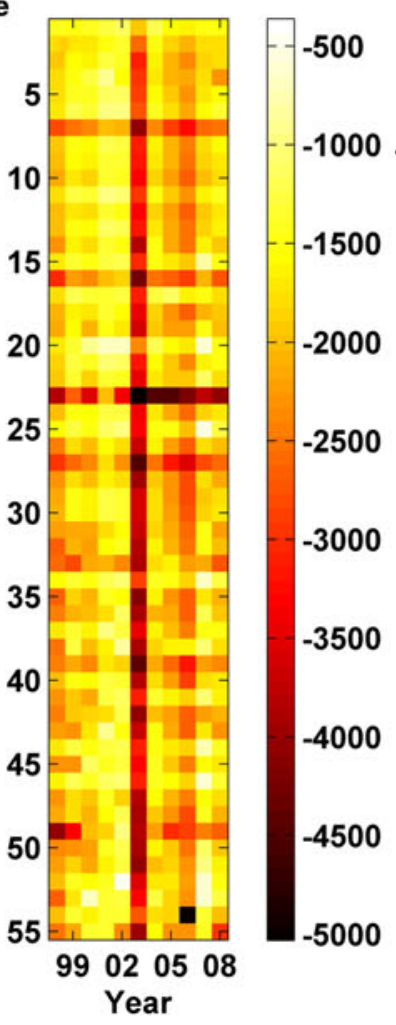

c
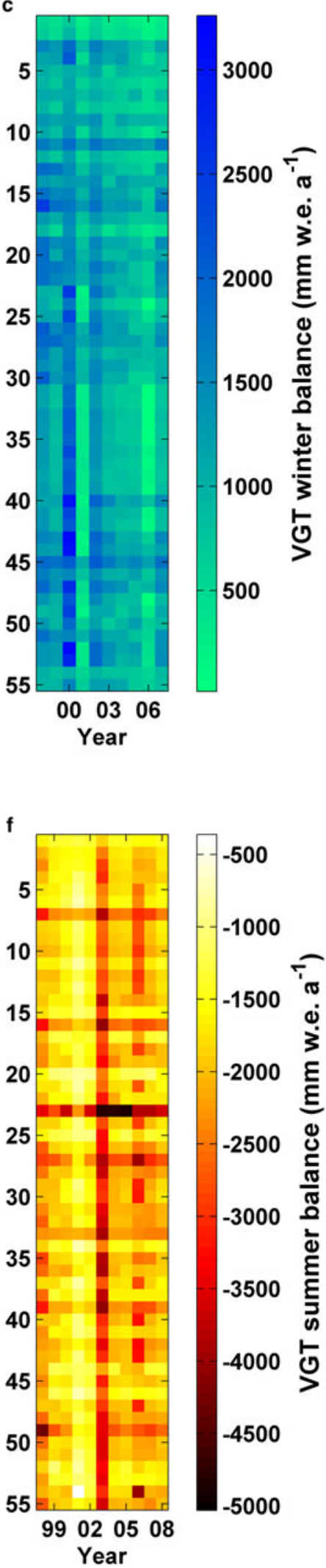

Fig. 4. Regression results for the 55 glaciers in terms of $R^{2}$, RMSE and seasonal MB. (a) RMSE (black curve) and $R^{2}$ (red curve) over the winter calibration period 1999-2008, for the 55 studied glaciers ranked by increasing RMSE. Time series of observed winter MB (b) and winter MB estimated with VGT (c) over 1999-2008. For (b) and (c), each horizontal row of coloured rectangles represents the MB time series of a glacier (the rectangle colour indicating the MB value). Lower panels (d)-(f): respective summer equivalents of graphs (a)-(c), over 1998-2008, for the 55 glaciers ranked by increasing RMSE. The glaciers ranking is not the same for the two seasons (winter and summer glacier ranking in Table S1). 
is smaller $\left(158 \mathrm{~mm}\right.$ w.e. $\left.\mathrm{a}^{-1}\right)$ than the range of annual errors acknowledged for the glaciological $M B$ measurements $\left(E_{\mathrm{obs}}= \pm 200-400 \mathrm{~mm}\right.$ w.e. $\left.\mathrm{a}^{-1}\right)$. RMSE $E_{\mathrm{w} \_ \text {cal }}$ ranges between $50 \mathrm{~mm}$ w.e. $\mathrm{a}^{-1}$ (for Gorner, \#1) and $260 \mathrm{~mm}$ w.e. $\mathrm{a}^{-1}$ (for Ciardoney, \#55), with third quartile and median values of 189 and $159 \mathrm{~mm}$ w.e. $\mathrm{a}^{-1}$, respectively. Even the highest $R M S E_{\mathrm{w}_{\text {_cal }}}$ are in the same range as the lower limit for $E_{\mathrm{obs}}$. Glaciers less well-ranked in terms of $R M S E_{\mathrm{w}_{-} \text {cal }}$ (Ciardoney, Aletsch, Cantun, respectively \#55, \#54, \#53) are not necessarily the least well-ranked in terms of $R_{\mathrm{w}}^{2}$. Cantun for example presents a relatively high $R M S E_{\mathrm{w} \_ \text {cal }}\left(237 \mathrm{~mm}\right.$ w.e. $\left.\mathrm{a}^{-1}\right)$ but also a high $R_{\mathrm{w}}^{2}$ of 0.89 because average winter MBs are higher for this glacier. Thus, the two metrics ( $R^{2}$ and RMSE) are not redundant for characterizing the linear relationships between $Z$ and observed $M B$ for all the glaciers.

As shown in Figure $4 \mathrm{~d}$, the correlation between $Z_{\mathrm{s}}$ and $B_{\mathrm{s} \text { obs }}$ is also high in summer but not as much as in winter: the mean $R_{\mathrm{s}}^{2}$ for the 55 glaciers is 0.74 , and the difference is also significant for the first quartile and median values (respectively 0.70 and 0.77 in summer instead of 0.79 and 0.89 in winter). $R_{\mathrm{s}}^{2}$ is between 0.52 (Clariden, \#55) and 0.88 (Sarennes, \#23). The difference between the minimum and maximum of $R_{\mathrm{s}}^{2}(0.36)$ is inferior to the same value in winter (0.66), indicating a lower spread of the correlation for summer. The mean $R M S E_{\mathrm{s}_{\text {c cal }}}$ of the estimated $B_{\mathrm{s} \vee V G T}$ for the 55 glaciers $\left(314 \mathrm{~mm}\right.$ w.e. $\mathrm{a}^{-1}$ ) is twice as large as in winter $\left(158 \mathrm{~mm}\right.$ w.e. $\mathrm{a}^{-1}$ ) but still acceptable compared with the error range of glaciological $\mathrm{MB}$ measurements. $R M S E_{\text {s_cal }}$ ranges between 134 and $528 \mathrm{~mm}$ w.e. $\mathrm{a}^{-1}$ (with third quartile and median values of respectively 355 and $299 \mathrm{~mm}$ w.e. $\mathrm{a}^{-1}$ ). Glaciers from source 2 (Table 1) present higher mean $R M S E_{\mathrm{s} \_ \text {cal }}$ and lower $R_{\mathrm{s}}^{2}\left(391 \mathrm{~mm}\right.$ w.e. $\mathrm{a}^{-1}$ and 0.70 respectively) than glaciers from source $1(325 \mathrm{~mm}$ w.e. $\mathrm{a}^{-1}$ and 0.77 respectively) and source $3(300 \mathrm{~mm}$ w.e. $\mathrm{a}^{-1}$ and 0.74 respectively). The summer $R M S E_{\mathrm{s} \text { cal }}$ range $\left(394 \mathrm{~mm}\right.$ w.e. $\left.\mathrm{a}^{-1}\right)$ is larger than in winter $(232 \mathrm{~mm}$ w.e. $\mathrm{a}^{-1}$ ) indicating a wider spread in $R M S E_{\mathrm{S}_{-} \text {cal }}$ during this season. Moreover, we observe that glaciers with a poor performance in summer do not necessarily present the same poor performance in winter (Table S1).

Figure $4 \mathrm{~b}, \mathrm{c}$ show $B_{\mathrm{w} \_ \text {obs }}$ and $B_{\mathrm{w} \_ \text {VGT }}$ time series estimated with SPOT/VGT, over the calibration period 1999-2008, for winter and for the 55 glaciers. By comparing Figure $4 \mathrm{~b}$ with $\mathrm{C}$, it is seen that for all glaciers the $B_{\mathrm{w} \_ \text {obs }}$ and $B_{\mathrm{w} \text { VGT }}$ time series are similar, illustrating that the 'optimized' relationships computed from SPOTNGT allow a good estimation of the interannual variations in winter MB over 1999-2008. We note that Aletsch (the biggest glacier in the European Alps), ranked 54th in winter (and with the lowest $R^{2}$ ), presents a 'flat' winter observed MB time series, with low interannual variability.

According to Figures $4 \mathrm{e}, \mathrm{f}, B_{\mathrm{s}_{-} \mathrm{VG}}$ time series are in agreement with $B_{\text {s_obs }}$ time series over 1998-2008. As in winter, the mean differences between $B_{\mathrm{s} \_ \text {obs }}$ and $B_{\mathrm{s} \text { VGT }}$ are the highest for 2 a with extreme summer MBs: 2003 (with strongly negative $M B$ values) and 2007 (a year with above average $M B)$. The very negative and atypical summer MB time series of Sarennes $(\# 23)$ is well estimated with SPOT/NGT $\left(R_{\mathrm{s}}^{2}\right.$ of 0.88 and $R M S E_{\mathrm{s}_{\text {cal }}}$ of $282 \mathrm{~mm}$ w.e. $\mathrm{a}^{-1}$ ).

By comparing Figures 6c, d (blue dots), we observe that the regression coefficient $\alpha$ values of all glaciers are much more scattered in summer than in winter. In winter, $\alpha_{\mathrm{w}}$ ranges between -2.7 and $-0.6 \mathrm{~mm}$ w.e. $\mathrm{a}^{-1} \mathrm{~m}^{-1}$, whereas $\alpha_{\mathrm{s}}$ ranges between -15 and $-1 \mathrm{~mm}$ w.e. $\mathrm{a}^{-1} \mathrm{~m}^{-1}$ in summer. For both seasons, we observe that the lower the absolute $\alpha$ value, the lower the RMSE over the calibration period.

\subsubsection{Performance for the average of all observed glaciers}

The mean $\mathrm{MB}$ time series averaged for all glaciers is also interesting to study as it illustrates glacier behaviour at the scale of the entire European Alps.

In winter (Fig. 5a), $\left\langle B_{\mathrm{w}_{-} \text {VGT }}\right\rangle$ globally fits well with $\left\langle B_{\mathrm{w}_{-} \text {obs }}\right\rangle$. Absolute mean $\mathrm{MB}$ errors $\left|M B E_{\mathrm{w}_{-} \text {cal }}\right|$ (i.e. the mean difference between $B_{\mathrm{w}}$ VGT and $B_{\mathrm{w} \text { obs }}$ for all the glaciers) are maximal in 2005 (175 mm w.e. $\left.\mathrm{a}^{-1}\right), 2001$ (110 $\mathrm{mm}$ w.e. $\mathrm{a}^{-1}$ ), and to a lesser extent, in 2007 (95 mm w.e. $\mathrm{a}^{-1}$ ) (Table 2). Nevertheless, these errors are small compared with the standard deviation of the observed winter $\mathrm{MB}$ of all glaciers $\sigma_{\mathrm{w} \text { obs }}$ computed for 2001, 2005 and 2007, respectively equal to 615,373 and $272 \mathrm{~mm}$ w.e. $\mathrm{a}^{-1}$.We also note that the two contrasting winter balance years in 2000 and 2001 are well captured by the model. In summer (Fig. 5b), $\left\langle B_{\mathrm{s} \_V G T}\right\rangle$ fits less well with $\left\langle B_{\mathrm{s} \text { obs }}\right\rangle$ than in winter although the largest interannual variations are captured. In 2003, we observe the lowest $\mathrm{MB}$ values reflecting the exceptional summer heat wave of 2003. Absolute mean MB errors $M B E_{\mathrm{s} \text { cal }}$ are the highest for 2007 (448 mm w.e. $\mathrm{a}^{-1}$ ) and 2003 (356 mm w.e. $\mathrm{a}^{-1}$ ). These summer errors are higher than winter errors but still inferior to $\sigma_{\text {s_obs }}$ of 2007 and 2003 (respectively 594 and $559 \mathrm{~mm} \mathrm{w.e.} \mathrm{a}^{-1}$ ) (Table 2). Larger errors in summer can be partly explained by higher interannual variability in summer observed MBs. If we consider the annual $\mathrm{MB}$ (sum of winter and summer $\mathrm{MB}$; Fig. 5c), the largest errors occur for 2007 and 2003 (respectively 582 and $411 \mathrm{~mm}$ w.e. $\mathrm{a}^{-1}$ ), as in summer.

Table 1. Summary of the linear regression results over the calibration period 1998/1999-2008 according to individual data sources and averaged for the 55 glaciers

\begin{tabular}{|c|c|c|c|c|c|}
\hline & & Source 1 (7 glaciers) & Source 2 (7 glaciers) & Source 3 (41 glaciers) & All glaciers (55) \\
\hline \multirow[t]{4}{*}{ Winter } & $R_{\mathrm{w}_{\text {ccal }}}^{2}$ & 0.76 & 0.72 & 0.88 & 0.84 \\
\hline & $R M S E_{\mathrm{w} \text { cal }}\left(\mathrm{mm}\right.$ w.e. $\left.\mathrm{a}^{-1}\right)$ & 160 & 141 & 160 & 158 \\
\hline & $\alpha_{\mathrm{w}}\left(\mathrm{mm}\right.$ w.e. $\left.\mathrm{a}^{-1} \mathrm{~m}^{-1}\right)$ & -1.16 & -0.92 & -1.56 & -1.56 \\
\hline & $\beta_{\mathrm{w}}\left(\mathrm{mm}\right.$ w.e. $\left.\mathrm{a}^{-1}\right)$ & 3626 & 3293 & 4231 & 4308 \\
\hline \multirow[t]{4}{*}{ Summer } & $R_{\mathrm{s} \text { cal }}^{2}$ & 0.77 & 0.70 & 0.74 & 0.74 \\
\hline & $R M S E_{\mathrm{s} \text { cal }}\left(\mathrm{mm}\right.$ w.e. $\left.\mathrm{a}^{-1}\right)$ & 325 & 391 & 300 & 314 \\
\hline & $\alpha_{\mathrm{s}}\left(\mathrm{mm}\right.$ w.e. $\left.\mathrm{a}^{-1} \mathrm{~m}^{-1}\right)$ & -4.39 & -6.69 & -5.16 & -5.25 \\
\hline & $\beta_{\mathrm{s}}\left(\mathrm{mm}\right.$ w.e. $\left.\mathrm{a}^{-1}\right)$ & 11579 & 19785 & 14573 & 14722 \\
\hline
\end{tabular}



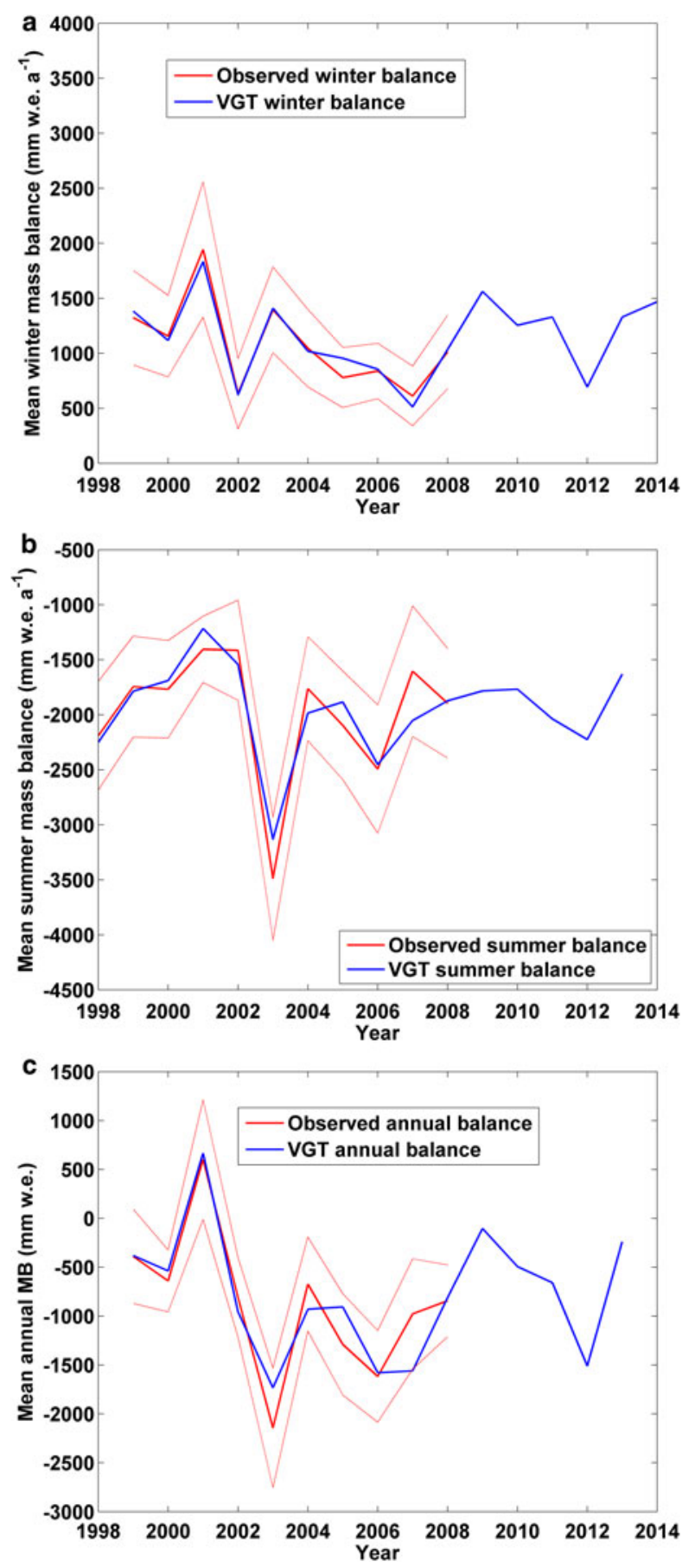

Fig. 5. Time series of mean observed $M B$ (red) over the calibration period and of mean VGT MB (blue) over the period covered by SPOT/VGT, averaged for the 55 glaciers. The dashed red curves represent the time series of observed $\mathrm{MB} \pm$ the standard deviation for all glaciers. (a) Winter MB for the calibration period, 19992008 and the period covered by SPOT/VGT, 1999-2014. (b) Summer MB for the calibration period, 1998-2008 and the period covered by SPOT/VGT, 1998-2013. (c) Annual MB (sum of winter and summer MBs) over 1999-2013.

The agreement between VGT MB estimations and observed $\mathrm{MB}$ over the calibration period presented above is satisfying. In order to test the robustness of our approach, we first perform a cross-validation of the 55 regressions to assess the temporal robustness and skills of the regression coefficients. We then compare seasonal VGT MB time series and independent observed MB data (not used for calibration) over the evaluation period 2009-2014.

\subsection{Cross-validation over the calibration period 1998/1999-2008}

Cross-validation results for the 55 optimized relations initially calibrated over 1998/1999-2008 indicate no negative skill score SS, except for Seewjinen in summer $\left(S S_{\mathrm{S}}=-0.08\right.$; Fig. 6b). This is consistent with the low $R_{\mathrm{s}}^{2}$ and high $R M S E_{\text {s_cal }_{1}}$ calculated for this glacier over the calibration period (Table S1). For most glaciers, the optimized individual relationships thus have skills to estimate the seasonal $M B$ over a simple average of the observed MB. In winter, SS values are higher $\left(\left\langle S S_{\mathrm{w}}\right\rangle=0.76\right)$ than in summer $\left(\left\langle S S_{\mathrm{s}}\right\rangle=\right.$ 0.55) (Table 3, Figs 6a, b). In winter, glaciers from Source 3 perform better in terms of $\left\langle S S_{\mathrm{w}}\right\rangle$ and $\left\langle R_{\mathrm{w} \_ \text {cross }}^{2}\right\rangle$ than others. This is consistent with their best performance for the calibration $\left(\left\langle R_{\mathrm{w} \_ \text {cal }}^{2}\right\rangle=0.88\right.$, Table 1$)$. $R M S E_{\mathrm{w} \_ \text {cross }}$ are slightly higher than $R M S E_{\mathrm{w}_{-} \text {cal }}$ (Fig. 6a), but they remain satisfactory with regard to $E_{\text {ref. }}$ In summer, $R M S E_{\mathrm{s}_{-} \text {cross }}$ are superior to $R M S E_{s_{-} \text {cal }}$ (Fig. 6b) and also on average slightly superior to $E_{\text {ref }}\left(\left\langle R M S E_{s_{-} \text {cross }}\right\rangle=440 \mathrm{~mm}\right.$ w.e. $\mathrm{a}^{-1}$; Table 3). Moreover, for both seasons, the higher the SS, the lower the RMSE and the lower the difference between the two RMSEs (derived from both calibration and test-cross) (Figs 6a, b). Only Aletsch Glacier in winter and Cengal Glacier in summer present satisfactory RMSEs (as regards to $E_{\text {ref }}$ ) and low SS. Therefore, for these two glaciers, despite their RMSE, their calibrated relationships present no particular skill over a simple average of their observed MBs.

In winter, we observe high consistency between $\alpha_{w_{-} \text {cross_best }}\left(\right.$ mean of the $N \alpha_{w_{-} \text {cross }}$ ) and the calibrated $\alpha_{\mathrm{w}}$ (Fig. 6c). Moreover, the standard deviations $\sigma\left(\alpha_{w_{-} \text {cross }}\right)$ in winter are low and close to an order of magnitude smaller than for $\alpha_{\mathrm{w}_{-} \text {cross_best }}($ Fig. 6e; Table 3); the same applies for $\sigma\left(\beta_{\mathrm{w}_{-} \text {cross }}\right)$. These results allow us to conclude that the calibrated relationships are robust and temporally stable in winter (except for Aletsch), despite the shortness of the time series used for the linear regression. The outcomes show the potential skill of the individual relations to accurately estimate the winter $\mathrm{MB}$ outside the calibration period. In summer, the consistency between $\alpha_{\text {s_cross_best }}$ and $\alpha_{\mathrm{s}}$ is also quite high, as in winter (Fig. 6d). Nevertheless, unlike in winter, the standard deviations $\sigma\left(\alpha_{s_{-} \text {cross }}\right)$ in summer are high, especially for glaciers with high $R M S E_{\text {s_cal }_{2}}$ (superior to 350-400 mm w.e. $\mathrm{a}^{-1}$ ) (Fig. 6f; Table 3). Therefore, in summer, we can conclude on the robustness and the temporal stability of about $60 \%$ of the 55 calibrated relationships (presenting an $R M S E_{\text {s_cal }_{\text {cal }}}<400 \mathrm{~mm}$ w.e. $\mathrm{a}^{-1}$ and a skill score $>0.65$ ). In order to test the robustness of our approach outside the calibration period 1998-2008, we then compare seasonal VGT MB time series and independent observed MB data (not used for calibration) over the evaluation period 2009-2014.

\subsection{Performance over the evaluation period 2009- 2013/2014}

The winter and summer MB averaged for all 55 glaciers estimated with SPOT/VGT (in blue) after 2008 are shown in Figure 5. In winter (Fig. 5a), $\left\langle B_{\mathrm{w}_{-} \mathrm{VGT}}\right\rangle$ values are generally above average over 2009-2014, except for 2012, where we note a strong decrease in $\left\langle B_{\mathrm{w}_{-} \mathrm{VGT}}\right\rangle$. In summer (Fig. 5b), $\left\langle B_{\mathrm{s}_{-} \mathrm{VGT}}\right\rangle$ is close to the average of 1998-2008, except for a notably negative MB during summer 2012. Table S2 (Supplementary Material) presents for each glacier, estimates 
Table 2. Mean mass balance error MBE averaged for all glaciers and standard deviation $\sigma$ of the observed MBs, per year and for the overall calibration period 1998/1999-2008

\begin{tabular}{|c|c|c|c|c|c|c|c|c|c|c|c|c|c|}
\hline & & 98 & 99 & 00 & 01 & 02 & 03 & 04 & 05 & 06 & 07 & 08 & 98/99-08 \\
\hline \multirow[t]{2}{*}{ Winter } & $\left|M B E_{\mathrm{w} \_c a l}\right|\left(\mathrm{mm}\right.$ w.e. $\left.\mathrm{a}^{-1}\right)$ & & 58 & 39 & 110 & 12 & 15 & 28 & 175 & 17 & 99 & 22 & 58 \\
\hline & $\sigma_{\mathrm{w} \_ \text {obs }}\left(\mathrm{mm}\right.$ w.e. $\left.\mathrm{a}^{-1}\right)$ & & 429 & 370 & 615 & 319 & 391 & 353 & 373 & 252 & 272 & 334 & 406 \\
\hline \multirow[t]{2}{*}{ Summer } & $\left|M B E_{\mathrm{s}_{-} \text {cal }}\right|\left(\mathrm{mm}\right.$ w.e. $\left.\mathrm{a}^{-1}\right)$ & 59 & 41 & 78 & 190 & 128 & 356 & 222 & 213 & 41 & 448 & 22 & 164 \\
\hline & $\sigma_{\text {s_obs }}\left(\mathrm{mm}\right.$ w.e. $\left.\mathrm{a}^{-1}\right)$ & 493 & 460 & 443 & 301 & 455 & 559 & 473 & 494 & 583 & 594 & 498 & 596 \\
\hline \multirow[t]{2}{*}{ Annual } & $\left|M B E_{\mathrm{a} \_ \text {cal }}\right|\left(\mathrm{mm}\right.$ w.e. $\left.\mathrm{a}^{-1}\right)$ & & 8 & 103 & 64 & 146 & 411 & 257 & 383 & 38 & 582 & 31 & 202 \\
\hline & $\sigma_{\text {a_obs }}\left(\mathrm{mm}\right.$ w.e. $\left.\mathrm{a}^{-1}\right)$ & & 482 & 316 & 611 & 405 & 613 & 481 & 518 & 468 & 564 & 368 & 483 \\
\hline
\end{tabular}
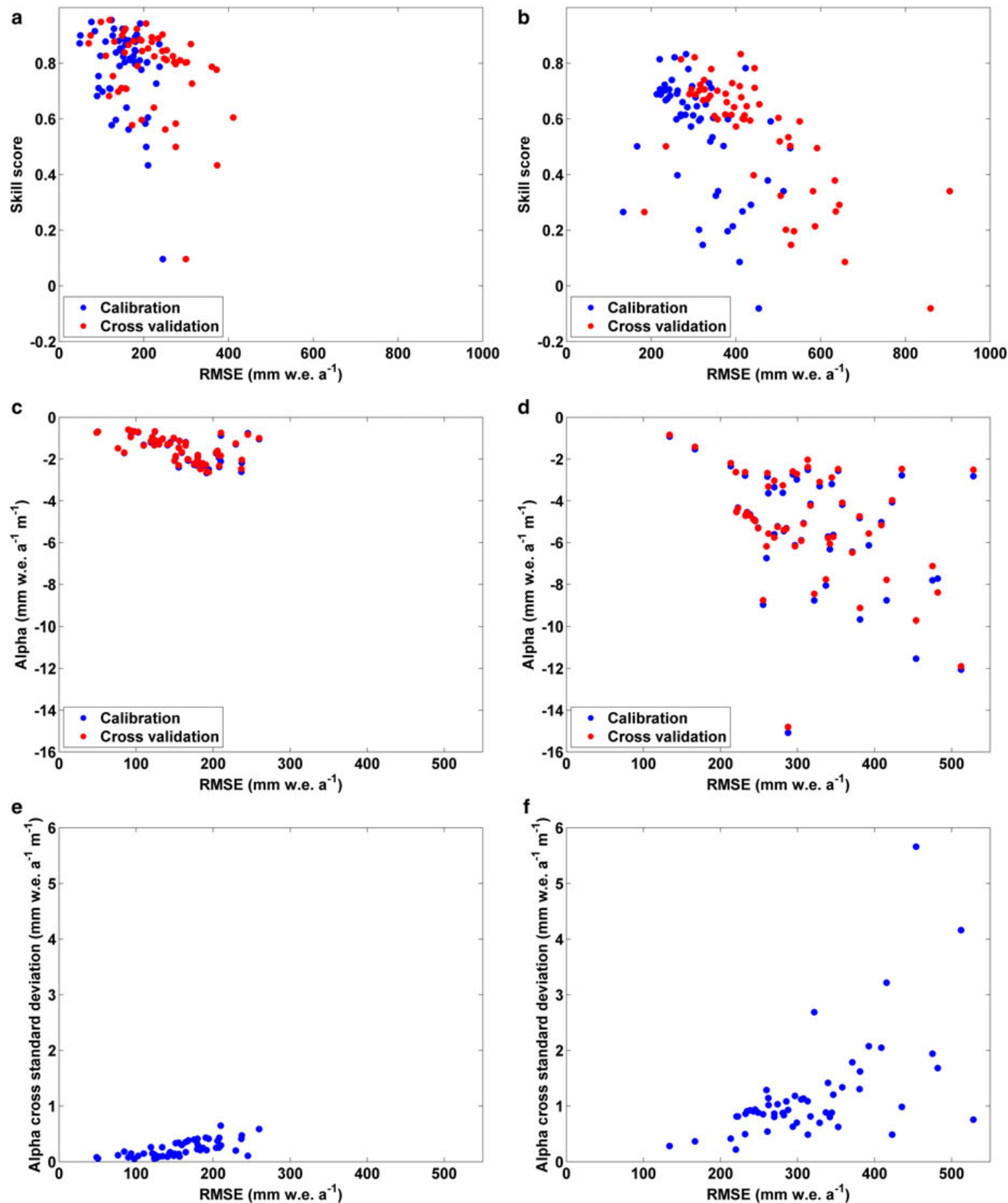

Fig. 6. Results of the cross-validation for all glaciers. Skill score as a function of RMSE computed for the calibration (blue) and for the test cross (red), in (a) winter and (b) summer. Alpha derived from the calibration (blue) and from the cross-validation (red) as a function of RMSE computed for the calibration, in (c) winter and (d) summer. Standard deviation of the alpha derived from the test-cross as a function of RMSE computed for the calibration, in (e) winter and ( $f$ ) summer. 
Table 3. Summary of the cross-validation results over the calibration period 1998/1999-2008 according to individual data sources and for the 55 glaciers

\begin{tabular}{|c|c|c|c|c|c|}
\hline & & Source 1 ( 7 glaciers) & Source 2 (7 glaciers) & Source 3 (41 glaciers) & All glaciers (55) \\
\hline \multirow[t]{7}{*}{ Winter } & $S S_{\mathrm{w}}$ & 0.55 & 0.59 & 0.79 & 0.76 \\
\hline & $R_{\mathrm{w}_{-} \text {cross }}^{2}$ & 0.73 & 0.72 & 0.84 & 0.82 \\
\hline & $R M S E_{\mathrm{w}_{\text {ccross }}}\left(\mathrm{mm}\right.$ w.e. $\left.\mathrm{a}^{-1}\right)$ & 240 & 190 & 219 & 222 \\
\hline & $\alpha_{\mathrm{w} \_ \text {cross_best }}\left(\mathrm{mm}\right.$ w.e. $\left.\mathrm{a}^{-1} \mathrm{~m}^{-1}\right)$ & -1.12 & -0.92 & -1.6 & -1.5 \\
\hline & $\sigma\left(\alpha_{\mathrm{w} \text { _cross_best }}\right)\left(\mathrm{mm}\right.$ w.e. $\left.\mathrm{a}^{-1} \mathrm{~m}^{-1}\right)$ & 0.25 & 0.16 & 0.24 & 0.24 \\
\hline & $\beta_{\mathrm{w} \_ \text {cross }}\left(\mathrm{mm}\right.$ w.e. $\left.\mathrm{a}^{-1}\right)$ & 3516 & 3287 & 4334 & 4230 \\
\hline & $\sigma\left(\beta_{\mathrm{w} \_ \text {cross }}\right)\left(\mathrm{mm}\right.$ w.e. $\left.\mathrm{a}^{-1}\right)$ & 546 & 396 & 514 & 518 \\
\hline \multirow[t]{7}{*}{ Summer } & $S S_{\mathrm{s}}$ & 0.59 & 0.59 & 0.55 & 0.55 \\
\hline & $R_{\mathrm{s}_{\text {cross }}}^{2}$ & 0.71 & 0.67 & 0.74 & 0.71 \\
\hline & $R M S E_{\mathrm{s}_{\text {c cross }}}\left(\mathrm{mm}\right.$ w.e. $\left.\mathrm{a}^{-1}\right)$ & 437 & 504 & 457 & 440 \\
\hline & $\alpha_{\mathrm{s} \_ \text {cross_best }}\left(\mathrm{mm}\right.$ w.e. $\left.\mathrm{a}^{-1} \mathrm{~m}^{-1}\right)$ & -5.19 & -6.62 & -4.30 & -5.08 \\
\hline & $\sigma\left(\alpha_{\mathrm{s} \_ \text {cross }}\right)\left(\mathrm{mm}\right.$ w.e. $\left.\mathrm{a}^{-1} \mathrm{~m}^{-1}\right)$ & 1.22 & 1.44 & 0.99 & 1.19 \\
\hline & $\beta_{\text {s_cross_best }}\left(\mathrm{mm}\right.$ w.e. $\left.\mathrm{a}^{-1}\right)$ & 14612 & 19570 & 11284 & 14188 \\
\hline & $\sigma\left(\beta_{\text {s_cross }}\right)\left(\mathrm{mm}\right.$ w.e. $\left.\mathrm{a}^{-1}\right)$ & 3874 & 4743 & 3145 & 3781 \\
\hline
\end{tabular}

of both winter and summer MB over 2009-2014 and 20092013 respectively. In order to evaluate these VGT MB calculations (over 2009-2014 for winter and 2009-2013 for summer), we now compare them with observed MBs available for a subset of the 55 glaciers used for the calibration (19 glaciers in winter and 13 in summer).

For winter, $70 \%$ of the computed $\mathrm{MB}$ present an error smaller than the estimated uncertainty in the direct measurements $E_{\text {obs max }}$ (Fig. 7a). We find the highest errors $M B E_{\mathrm{w}_{\text {eveval }}}$ for Sarennes and Ciardoney $(-1015 \mathrm{~mm}$ w.e. in 2009 and $-850 \mathrm{~mm}$ w.e. in 2011). This result is not surprising as these glaciers are subject to a high $R M S E_{\mathrm{w}_{-} \text {cal }}$ Over the calibration period (Table S1). 2011 and 2013 are the most poorly estimated years (RMSE $E_{\mathrm{w}_{-} \text {eval }}$ of 587 and $501 \mathrm{~mm}$ w.e.), whereas 2010 and 2014 are best represented $\left(R M S E_{\mathrm{w} \text { eval }}\right.$ of 252 and $245 \mathrm{~mm}$ w.e.; Table 4). $R M S E_{\mathrm{w} \text { eval }}$ calculated from all data in the evaluation period $(n=66)$ is $411 \mathrm{~mm}$ w.e. $\mathrm{a}^{-1}$ and thus nearly three times larger than the average $R M S E_{\mathrm{w}_{\text {cal }}}\left(150 \mathrm{~mm}\right.$ w.e. $\left.\mathrm{a}^{-1}\right)$ computed for the same subset of 19 glaciers over the calibration period. However, $R M S E_{w_{-} \text {eval }}$ is still comparable with $E_{\text {obs } \max }$ and the mean $M B$ error $M B E_{\mathrm{w}_{-} \text {eval }}$ is close to zero $(16 \mathrm{~mm}$ w.e. $\mathrm{a}^{-1}$ ), suggesting that $B_{\mathrm{w}}$ VGT $_{\text {e }}$ estimations are unbiased. To sum it up, our approach is able to estimate the winter
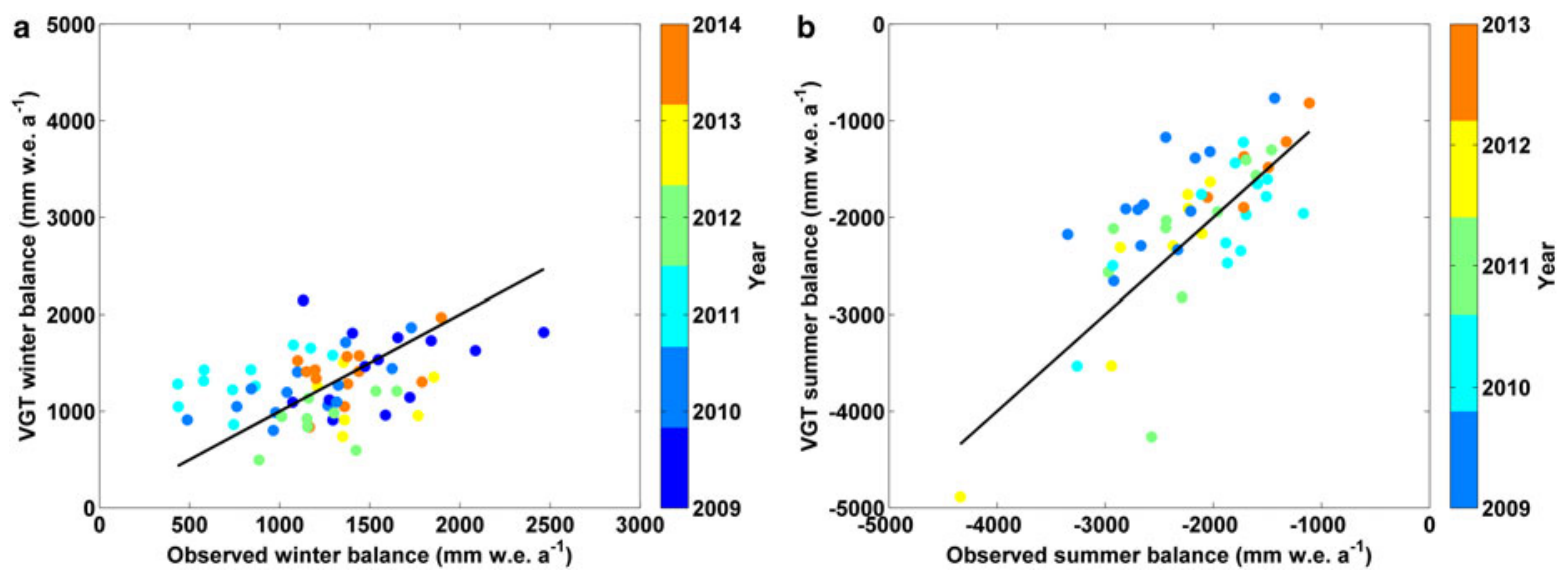

Fig. 7. Seasonal mass balances estimated with SPOT/VGT as a function of observed (a) winter and (b) summer MBs for glaciers over the evaluation period 2009-2014. The 1:1 agreement is plotted (bold line). The uncertainty in each MB measurement $E_{\mathrm{obs}} \max ( \pm 400 \mathrm{~mm}$ w.e. $\mathrm{a}^{-1}$ ) is not represented for the sake of clarity.

Table 4. MB error MBE and RMSE per year and for the overall evaluation period 2009-2013/2014

\begin{tabular}{|c|c|c|c|c|c|c|c|c|}
\hline & & 2009 & 2010 & 2011 & 2012 & 2013 & 2014 & $2009-2013 / 14$ \\
\hline \multirow[t]{3}{*}{ Winter } & Number of observed MB available & 13 & 13 & 11 & 9 & 6 & 14 & 66 \\
\hline & $M B E_{\mathrm{w} \text { eval }}\left(\mathrm{mm}\right.$ w.e. $\left.\mathrm{a}^{-1}\right)$ & -111 & 95 & 546 & -326 & -362 & 25 & 16 \\
\hline & $R M S E_{\mathrm{w} \_ \text {eval }}\left(\mathrm{mm}\right.$ w.e. $\left.\mathrm{a}^{-1}\right)$ & 460 & 252 & 587 & 394 & 502 & 245 & 411 \\
\hline \multirow[t]{3}{*}{ Summer } & Number of observed MB available & 12 & 13 & 10 & 8 & 6 & & 49 \\
\hline & $M B E_{\mathrm{s} \text { eval }}\left(\mathrm{mm}\right.$ w.e. $\left.\mathrm{a}^{-1}\right)$ & 664 & -132 & 23 & 78 & 140 & & 162 \\
\hline & $R M S E_{\text {s_eval }}\left(\mathrm{mm}\right.$ w.e. $\left.\mathrm{a}^{-1}\right)$ & 756 & 432 & 660 & 424 & 230 & & 561 \\
\hline
\end{tabular}


MB out of the calibration period for glaciers in the Alps with an acceptable mean overall error and without bias.

In summer, $60 \%$ of the computed MB present an error inferior or equal to $E_{\text {obs max }}$ (Fig. $7 \mathrm{~b}$ ). Largest errors $M B E_{\text {s_eval }}$ are about two (to three) times superior to $E_{\text {obs } \max }$ (e.g. Gietro with an error of $1695 \mathrm{~mm}$ w.e. $\mathrm{a}^{-1}$ in 2011) (Table 4). 2009 and 2011 are poorly estimated (resp. $R M S E_{\text {s_eval }}$ of 756 and $660 \mathrm{~mm}$ w.e.), but summer 2013 is correctly reproduced (low $R M S E_{\mathrm{s}_{\text {enval }}}$ of $230 \mathrm{~mm}$ w.e.). $R M S E_{\mathrm{s} \text { eval }}$ calculated for the 49 evaluation points $(561 \mathrm{~mm}$ w.e. $\mathrm{a}^{-1}$ ) is $\sim 1.5$ times larger than the RMSE calculated over the calibration period for the subset of 13 glaciers used for evaluation (RMSE $E_{\mathrm{s}_{\text {cal }}}=368 \mathrm{~mm}$ w.e. $\left.\mathrm{a}^{-1}\right)$. $R M S E_{\mathrm{s} \text { eval }}$ is also higher than winter $R M S E_{\mathrm{w} \text { eval }}$ and than $E_{\text {obs max. }}$ The mean $M B E_{\text {s_eval }}$ for the 49 points is not negligible $\left(162 \mathrm{~mm}\right.$ w.e. $\left.\mathrm{a}^{-1}\right)$, which indicates that $B_{\mathrm{s} \_ \text {VGT }}$ estimations are slightly positively biased during 20092013. This positive bias is mainly due to a strong bias $(664$ $\mathrm{mm}$ w.e. $\mathrm{a}^{-1}$ ) during summer 2009. No obvious explanation was found for this anomalous year. Excluding summer 2009, the $M B E_{\mathrm{s} \text { eval }}$ is reduced to $52 \mathrm{~mm}$ w.e. $\mathrm{a}^{-1}$. However, validation is made with fewer points in summer than in winter. Furthermore, glaciers used for evaluation in summer are not the best performers over the calibration period: the mean $R M S E_{\mathrm{s}_{-} \text {cal }}$ of the 13 evaluation glaciers $(368 \mathrm{~mm}$ w.e. $\mathrm{a}^{-1}$ ) is higher than the mean $R M S E_{\mathrm{s} \text { cal }}$ of the entire (55 glaciers) dataset $\left(318 \mathrm{~mm}\right.$ w.e. $\left.\mathrm{a}^{-1}\right)$.

Observed MB measurements for more glaciers and more years will be welcome to improve the robustness of the linear regressions between $\mathrm{MB}$ and $Z$ in summer and to provide a more representative error $R M S E_{\mathrm{s}_{-} \text {eval }}$ on the $M B$ estimated with SPOT/VGT.

\section{DISCUSSION AND PERSPECTIVES}

\subsection{Method performance}

Our method performs better in winter than in summer because it is based on the interannual dynamics of the altitudinal snow cover distribution to retrieve the interannual variation of seasonal MBs. In summer, the interannual dynamics are more difficult to capture as there is less snow. The lower number of snow-covered pixels in summer than in winter constitutes in fact a limit to retrieve smooth curves of altitudinal NDSI distribution. To justify this hypothesis, we estimate for each season, the mean number of pixels $N_{p}$ with a NDSI higher than 0.2 in each optimized WOSM sizes centred on Clariden Glacier. This glacier was chosen for its much lower performance in summer $\left(R_{\mathrm{s}}^{2}=\right.$ $0.52 ; R M S E_{\mathrm{s}_{\text {cal }}}=528 \mathrm{~mm}$ w.e. $\left.\mathrm{a}^{-1}\right)$ than in winter $\left(R_{\mathrm{w}}^{2}=\right.$ 0.92; $R M S E_{\mathrm{w} \_ \text {cal }}=130 \mathrm{~mm}$ w.e. $\left.\mathrm{a}^{-1}\right)$. At Clariden, the optimized WOSM for winter $(29 \mathrm{~km} \times 29 \mathrm{~km})$, gives a value of $N_{p}$ that is $\sim 6$ times higher in winter (840) than in summer (144). With the optimized summer WOSM $(225 \mathrm{~km} \times 225$ $\mathrm{km}), N_{p}$ is $\sim 12$ times higher for winter (19971) than for summer (1541). Thus, $N_{p}$ increases with WOSM size for both seasons.

This justifies the enlargement of the optimized WOSM* in summer in order to integrate more snow cover variability (Fig. 8). The distribution of WOSM* sizes is more spread towards larger windows: the median WOSM* side length is $119 \mathrm{~km}$ in summer against $43 \mathrm{~km}$ in winter. The need to increase the window size in summer suggests relatively homogeneous snow variations in summer across the Alps. This result is in agreement with the homogeneous summer ablation observed on glaciers across the entire Alpine Arc (Vincent and others, 2004). Pelto and Brown (2012) also noted a similarity of summer ablation across glaciers in the North Cascades.

Another reason for the difference in results between the seasons might be the cloud interpolation. For each season, we calculate the percentage of interpolated pixels for glaciers with low RMSE (inferior to the first quartile value) and high RMSE (superior to the third quartile), averaged over the calibration period. In winter, the mean percentage of interpolated pixels is large (4\%) and the difference between high and low RMSE glaciers is small: the mean difference over the $1999-2014$ period is $0.13 \%$. In summer, a striking difference is observed between glaciers with high and low RMSE: the mean difference of the interpolated pixels percentages $(0.64 \%)$ is more than four times larger than in winter. Therefore, the temporal interpolation seems to have more impact in summer than in winter. Our hypothesis to explain this observation is that the cloud mask performs less well for some glaciers in summer, but this needs to be further explored.

The effect of pixels contaminated by undetected clouds can also be another reason explaining the reduced performance for summer. The spectral signatures in the available bands of clouds and snow are close, indicating that cloudy
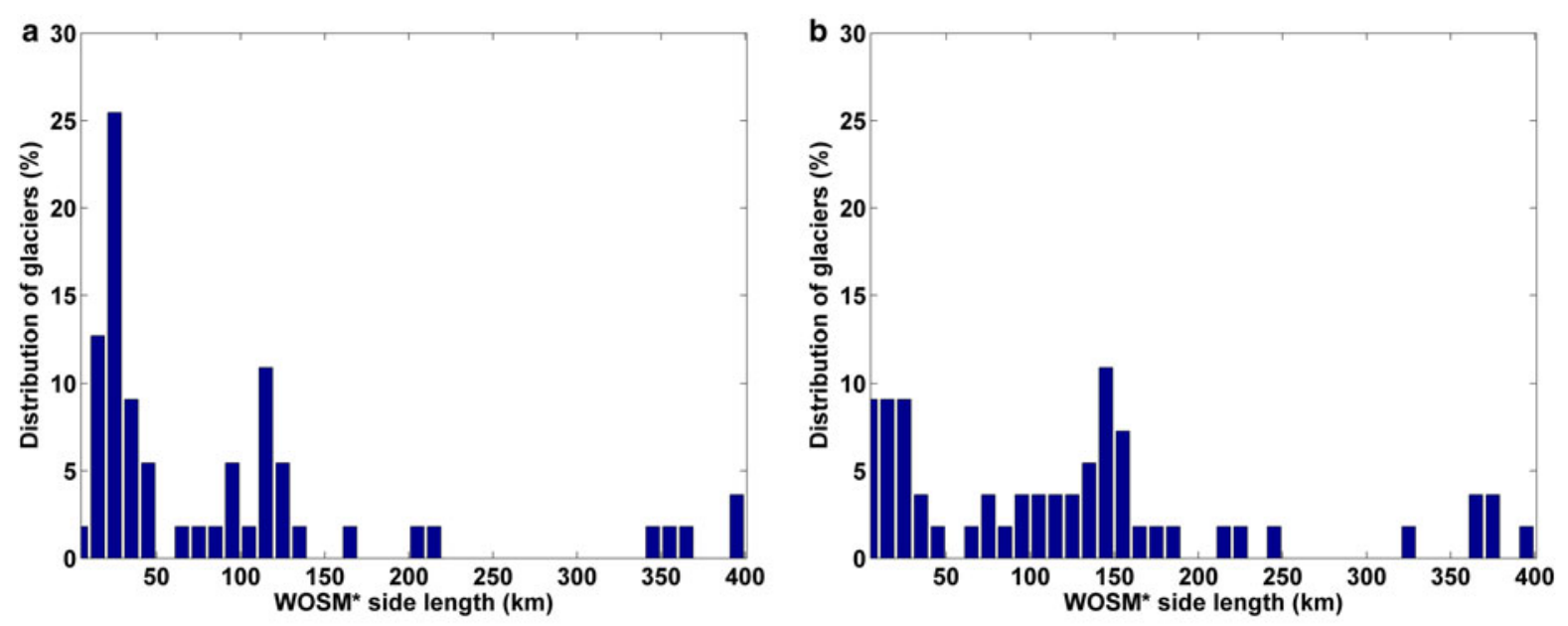

Fig. 8. Distribution of glaciers (\%) as a function of their WOSM* side length (a) in winter and (b) in summer. 
and snow-covered pixels have similar NDSI values. The error in a pixel NDSI value caused by a cloud is smaller for a snowcovered pixel than for a snow-free pixel. As there is less snow in summer than in winter, undetected clouds may impact more NDSI and snow detection in summer.

Despite the difference in performances between the seasons, we can highlight the ability of the approach to capture the extreme summer balance in 2003 and the two contrasting winter balance years in 2000 and 2001.

The performance of our method during the calibration (in terms of $R^{2}$ and RMSE) also varies with the source of the $\mathrm{MB}$ data. The best results are obtained with glaciers from source 3 (particularly for winter). The year-to-year variability in this dataset is based on meteorological time series (temperature, precipitation) and distributed modelling. As NDSI and interannual snow cover dynamics are also driven by meteorological parameters, we expected to find a good agreement but we are unable to conclude on the robustness of the method to estimate MB. However, a satisfying mean error for the evaluation period, assessed only with $M B$ data from sources 1 and 2, strengthens the robustness of the method. In fact, these MBs are closer to 'reality' as they are composed of in situ glaciological measurements. Nevertheless, MB data from sources 1 and 2 are also subject to uncertainties. In particular, for Aletsch Glacier (from source 2), the largest glacier of the Alps $\left(83 \mathrm{~km}^{2}\right)$, the lowest $R_{\mathrm{w}}^{2}(0.31)$ for winter was found. A possible explanation for the poor performance of our approach for Aletsch is that its ablation area reaches to relatively low elevation. It is thus snow-free for a considerable part of the period used for winter balance estimate (October to April). Winter MB data for Aletsch Glacier thus include both accumulation and melting, whereas the NDSI approach for winter is optimized to represent snow accumulation, as for the other glaciers.

\subsection{Perspectives}

A limitation of the proposed methodology is the impossibility (in some rare cases) to estimate the seasonal MB after the calibration period. This happens only in summer, specifically in 2009 and 2011 for Sarennes, and for Vernagt in 2012. In those particular cases, the NDSI value optimizing the linear relationships between $Z$ and $M B$ over the calibration period 1998-2008 does not intersect the NDSI altitudinal distribution curves: in both cases the curves are below the NDSI value. Thus, no MB can be retrieved. We note that for these two glaciers the optimized WOSM side lengths are among the smallest $(5 \mathrm{~km}$ for Sarennes and $21 \mathrm{~km}$ for Vernagt). If we increase the WOSM sizes, we can recover summer MB estimations for these years and these two glaciers but at the cost of degrading the regression quality $\left(R_{\mathrm{s}}^{2}\right.$ and $\left.R M S E_{\mathrm{S}_{\text {cal }}}\right)$ over the calibration period, mainly for Vernagt $\left(R_{\mathrm{s}}^{2}\right.$ decreases from 0.75 to 0.60 and $R M S E_{\mathrm{s} \_ \text {cal }}$ increases from 262 to $332 \mathrm{~mm}$ w.e. $\mathrm{a}^{-1}$ ). An objective criterion is being analysed to determine a WOSM side length threshold $>5 \mathrm{~km}$ in order to get NDSI altitudinal curves representative enough of the altitudinal snow cover distribution.

An important outlook of this study is to achieve a better cloud detection as an under/over estimation of cloudy pixels impacts snow-cover monitoring, especially in summer.

Another perspective to improve our summer results could be to couple our methodology with a melt model that is able to provide information on the short-term dynamics of melting.

One of this study's aim is to perform real-time seasonal $M B$ monitoring with daily low-resolution optical imagery for a large sample (here 55) of Alpine glaciers. Low resolution optical satellite images are available $2-3 d$ after the acquisition dates, implying that seasonal snow cover and seasonal $M B$ could be estimated a few weeks after the end of each season. Moreover, the method could also allow for glaciers with recently initialized $\mathrm{MB}$ series to extend them backwards in timer, for example by using the Advanced Very High Resolution Radiometer satellite data available since 1978. Interrupted $\mathrm{MB}$ time series could be reconstructed as well.

The ultimate and long-term goal of this work is to apply the method at large scales (i.e. thousands of glaciers in a mountain range for which no or very few direct $M B$ data are available). Therefore, the next step is to assess how accurately the approach can estimate the MB of an unmeasured glacier. For that purpose, it is necessary to build and apply a generic transposable relation between $Z$ and $M B$ with fixed parameters. The sensitivity of the coefficients of the linear regressions towards explicative factors (in particular topographic factors such as glacier size, aspect, etc.) or the variations of the optimized NDSI value and WOSM size need to be investigated in order to determine explicit and objective criteria to build a generic relation. Currently, the variability of alpha and beta remains a little too large (even in winter) to easily and in a satisfactory way obtain a simple generic relationship.

\section{CONCLUSION}

In this study, we have described an empirical method to estimate seasonal MBs of Alpine glaciers from kilometric resolution optical SPOTNGT images. From seasonal snow cover maps of the Alps derived for each year over 1998-2014, a regional mean snow altitude of a region surrounding each glacier is derived for 55 glaciers with MB data. Promising linear relationships between this regional mean snow altitude and observed seasonal MBs have been found over 19982008. The explained variance in winter is high for all glaciers $\left(R^{2}=0.84\right.$ on average) and the mean RMSE is low $(161 \mathrm{~mm}$ w.e. $\left.\mathrm{a}^{-1}\right)$. Results are not as good for summer but the explained variance is acceptable $\left(R^{2}=0.73\right)$ and the mean RMSE $\left(318 \mathrm{~mm}\right.$ w.e. $\mathrm{a}^{-1}$ ) is still in the range of errors associated with glaciological MB measurements (typically from \pm 200 to $400 \mathrm{~mm}$ w.e. $\mathrm{a}^{-1}$ ). Cross-validation of the 55 individual linear regressions allows assessment of the temporal stability and the robustness of all the derived relationships in winter and of $\sim 60 \%$ in summer. Estimations of seasonal MB over 2009-2014 is also performed for these 55 glaciers, and a mean global error is calculated for some estimates, based on a more limited dataset of observed MBs. We are able to estimate winter MB with an acceptable mean global error (405 $\mathrm{mm}$ w.e. $\mathrm{a}^{-1}$ ) and without bias. In summer, the mean error of MB estimation over 2009-2014 is higher $\left(561 \mathrm{~mm}\right.$ w.e. $\mathrm{a}^{-1}$ ) but less observed MB measurements are available for validating the regressions during this season. Moreover, the subset of glaciers used for evaluation in summer tends to perform more poorly during calibration. Still, these results are promising and estimates of the seasonal MB could be performed as soon as the SPOT/NGT data (or data from similar satellites) are available and processed. A real-time seasonal MB 'monitoring' is thus conceivable, a 
few weeks after the end of each season for a large sample (here 55) of Alpine glaciers.

Our method performs better in winter than in summer. This is mainly explained by the fact that interannual dynamics of altitudinal snow cover distribution is more difficult to capture in summer as there is less snow. We also highlight the fact that interpolation of cloudy pixels has more impact in summer than in winter. However, an in-depth analysis needs to be carried out. The greater accuracy in winter emphasizes the value of this method over the classical snowline approach that does not provide any estimate in winter when accumulation area ratio is $100 \%$.

The SPOT/VGT mission ended in May 2014 but the PROBA-V satellite, launched in May 2013, ensures continuity and has been providing data since October 2013, with images at $1 \mathrm{~km}, 300 \mathrm{~m}$ and $100 \mathrm{~m}$ resolution. A comparison of snow cover and $\mathrm{MB}$ estimates derived from SPOT/VGT and from PROBA-V $1 \mathrm{~km}$ for the period of overlap (winter 2013-2014) is underway in order to extend MB data after 2015.

\section{SUPPLEMENTARY MATERIAL}

The supplementary material for this article can be found at http://dx.doi.org/10.1017/jog.2016.78.

\section{ACKNOWLEDGEMENTS}

We acknowledge the WGMS for the mass-balance data. We also thank all the observers who contributed to collect the seasonal mass balances and shared them with the community through the WGMS database. We are grateful to VITO and Belspo for the SPOT/VGT satellite images distribution, and the financial and scientific support to carry out this study. We acknowledge support from the CNES/TOSCA programme (in particular Juliette Lambin) as well as funding of a Ph.D. fellowship by VITO/CLS (and especially Eric Gontier, VITO and Estelle Obligis, CLS). We thank the Scientific Editor, David Rippin and two anonymous reviewers for their comments and suggestions which significantly improved the manuscript. This article is also a tribute to Gilbert Saint and his vision during the early 90s, of what an operational satellite mission should be.

\section{REFERENCES}

Abermann J, Fischer A, Lambrecht A and Geist T (2010) On the potential of very high-resolution repeat DEMs in glacial and periglacial environments. Cryosphere, 4, 53-65 (doi: 10.5194/ tc-4-53-2010)

Arnell NW (2004) Climate change and global water resources: SRES emissions and socio-economic scenarios. Glob. Environ. Chang., 14(1), 31-52 (doi: 10.1016/j.gloenvcha.2003.10.006)

Berthelot B (2004) Snow detection on VEGETATION data. Improvement of cloud screening

Berthier E and 10 others (2014) Glacier topography and elevation changes from Pléiades very high resolution stereo images. Cryosph. Discuss., 8(5), 4849-4883 (doi: 10.5194/tcd-8-48492014)

Braithwaite RJ (1984) Can the mass balance of a glacier be estimated from its equilibrium line altitude. J. Glaciol., 30(106), 364-368

Braithwaite RJ, Konzelmann TC, Marty C and Olesen OB (1998) Errors in daily ablation measurements in northern Greenland, 1993-94, and their implications for glacier climate studies. J. Glaciol., 44(148), 583-588
Chaponnière A and 6 others (2005) International Journal of Remote A combined high and low spatial resolution approach for mapping snow covered areas in the Atlas mountains. Int. J. Remote Sens., 26(13), 2755-2777

Cogley JG and Adams WP (1998) Mass balance of glaciers other than the ice sheets. J. Glaciol., 44(147), 315-325

Cox LH and March RS (2004) Comparison of geodetic and glaciological mass-balance techniques, Gulkana Glacier, Alaska, U.S.A. J. Glaciol., 50(170), 363-370 (doi: 10.3189/ 172756504781829855)

Crane RG and Anderson M (1984) Satellite discrimination of snow/ cloud surfaces. Int. J. Remote Sens., 5(1), 213-223

Deronde B and 6 others (2014) 15 years of processing and dissemination of SPOT-VEGETATION products. Int. J. Remote Sens., 35(7), 2402-2420 (doi: 10.1080/01431161.2014.883102)

Dozier J (1989) Spectral signature of alpine snow cover from the Landsat Thematic Mapper. Remote Sens. Environ., 28, 9-22 (doi: 10.1016/0034-4257(89)90101-6)

Dubertret F (2012) Following snow cover dynamics over Mediterranean mountains: combining high and low resolution satellite imagery too assess snow cover on a daily basis

Duchemin B and Maisongrande P (2002) Normalisation of directional effects in 10-day global syntheses derived from VEGETATION/ SPOT: I. Investigation of concepts based on simulation. Remote Sens. Environ., 81(1), 90-100 (doi: 10.1016/S0034-4257(01) 00337-6)

Dyurgerov MB and Meier MF (2002) Glacier mass balance and regime: data of measurements and analysis

Farr TG and Kobrick M (2000) Transactions of the American Geophysical Union. Amer. Geophys. Union EOS, 81, 583-585

Fortin J, Bernier $M$, El Battay $A$, Gauthier $Y$ and Turcotte $R$ (2001) Estimation of surface variables at the sub-pixel level for use as input to climate and hydrological models. In Proc. VEGETATION 2000 Conf.. http://www.spot-vegetation.com/ pages/vgtprep/vgt2000/fortin.html

Gardelle J, Berthier E, Arnaud Y and Kääb A (2013) Region-wide glacier mass balances over the Pamir-Karakoram-Himalaya during 1999-2011. Cryosph., 7(4), 1263-1286 (doi: 10.5194/ tc-7-1263-2013)

Gardner AS and 15 others (2013) A reconciled estimate of Glacier contributions to sea level rise: 2003 to 2009. Science (80-.) 852 (doi: 10.1126/science.1234532)

Haeberli W and Beniston M (1998) Change climate and its impacts on Glaciers and permafrost in the Alps. Res. Mt. Area Dev. Eur., 27(4), 258-265

Hall DK and Riggs GA (2007) Accuracy assessment of the MODIS snow products t. Hydrol. Process. 21, 1534-1547 (doi: 10.1002/hyp)

Hall DK, Riggs GA and Salomonson VV (1995) Development of methods for mapping global snow cover using moderate resolution imaging spectroradiometer data. Remote Sens. Environ., 54(2), 127-140 (doi: 10.1016/0034-4257(95)00137-P)

Hall DK, Foster JL, Verbyla DL, Klein AG and Bensont CS (1998) Assessment of snow-cover mapping accuracy in a variety of vegetation-cover densities in Central Alaska. Remote Sens. Environ., 66, 129-137

Hall DK, Riggs GA, Salomonson VV, DiGirolamo NE and Bayr KJ (2002) MODIS snow-cover products. Remote Sens. Environ., 83(1-2), 181-194 (doi: 10.1016/S0034-4257(02)00095-0)

Hock R (1999) A distributed temperature-index ice- and snowmelt model including potential direct solar radiation. J. Glaciol., 45 (149), 101-111. http://search.ebscohost.com/login.aspx?direct= true $\& \mathrm{db}=\mathrm{pcl} \& \mathrm{AN}=1791188 \&$ lang $=$ fr \&site $=$ eds-live

Hofer M, Mölg T, Marzeion B and Kaser G (2010) Empiricalstatistical downscaling of reanalysis data to high-resolution air temperature and specific humidity above a glacier surface (Cordillera Blanca, Peru). J. Geophys. Res. Atmos., 115, 1-15 (doi: 10.1029/2009JD012556)

Holben BN (1986) Characteristics of maximum-value composite images from temporal AVHRR data. Int. J. Remote Sens., 7(11), 1417-1434 (doi: 10.1080/01431168608948945) 
Hulth J, Rolstad Denby C and Hock R (2013) Estimating glacier snow accumulation from backward calculation of melt and snowline tracking. Ann. Glaciol., 54(62), 1-7 (doi: 10.3189/ 2013AoG62A083)

Huss M (2011) Present and future contribution of glacier storage change to runoff from macroscale drainage basins in Europe. Water Resour. Res., 47(7) (doi: 10.1029/2010WR010299)

Huss M (2013) Density assumptions for converting geodetic glacier volume change to mass change. Cryosph., 7(3), 877-887 (doi: 10.5194/tc-7-877-2013)

Huss M, Bauder A, Funk M and Hock R (2008) Determination of the seasonal mass balance of four Alpine glaciers since 1865. J. Geophys. Res., 113(F1), F01015 (doi: 10.1029/2007JF000803)

Huss M, Hock R, Bauder A and Funk M (2010a) 100-year mass changes in the Swiss Alps linked to the Atlantic Multidecadal Oscillation. Geophys. Res. Lett., 37(10) (doi: 10.1029/2010 GL042616)

Huss M, Usselmann S, Farinotti D and Bauder A (2010b) Glacier mass balance in the south-eastern Swiss Alps since 1900 and perspectives for the future. Erdkunde, 64(2), 119-140 (doi: 10.3112/ erdkunde.2010.02.02)

Huss $M$ and 6 others (2013) Towards remote monitoring of subseasonal glacier mass balance. Ann. Glaciol., 54(63), 85-93 (doi: 10.3189/2013AoG63A427)

Huss M, Dhulst L and Bauder A (2015) New long-term mass-balance series for the Swiss Alps. J. Glaciol., 61(227), 551-562 (doi: 10.3189/2015JoG15J015)

IPCC (2013) Observations: Cryosphere. In Climate Change 2013: The Physical Science Basis. Contribution of Working Group I to the Fifth Assessment Report of the Intergovernmental Panel on Climate Change (doi: 10.1017/CBO9781107415324.012)

Irish RR (2000) Landsat 7 automatic cloud cover assessment. Int. Soc. Opt. Eng., 4049, 348-355. http://dx.doi.org/10.1117/12. 410358

Jóhannesson T and 7 others (2013) Ice-volume changes, bias estimation of mass-balance measurements and changes in subglacial lakes derived by Lidar mapping of the surface of Icelandic glaciers. Ann. Glaciol., 54, 63-74 (doi: 10.3189/2013AoG63A422)

Kääb A, Treichler D, Nuth C and Berthier E (2015) Brief communication: contending estimates of 2003-2008 glacier mass balance over the Pamir-Karakoram-Himalaya. Cryosphere, 9(2), 557-564 (doi: 10.5194/tc-9-557-2015)

Kaser G, Fountain AG and Jansson P (2003) A manual for monitoring the mass balance of mountain glaciers with particular attention to low latitude characteristics. A contribution to the UNESCO HKHFriend programme. Paris, France

Kaser G, Grosshauser M and Marzeion B (2010) Contribution potential of glaciers to water availability in different climate regimes. Proc. Natl. Acad. Sci. USA, 107(47), 20223-7 (doi: 10.1073/ pnas.1008162107)

Kropáček J, Neckel N and Bauder A (2014) Estimation of mass balance of the Grosser Aletschgletscher, Swiss Alps, from ICESat Laser Altimetry Data and Digital Elevation Models. Remote Sens., 6(6), 5614-5632 (doi: 10.3390/rs6065614)

Kuhn M (1989) The response of the equilibrium line altitude to climatic fluctuations: theory and observations. In Oerlemans J ed. Glacier fluctuations and climatic change. Kluwer Academic Publishers, Dordrecht, 407-417

LaChapelle E (1962) Assessing glacier mass budgets by reconnaissance aerial photography. J. Glaciol., 4(33), 290-297

Leonard KC and Fountain AG (2003) Map-based methods for estimating glacier equilibrium-line altitudes. J. Glaciol., 49(166), 329-336

Lissens G, Kempencers P, Fierens F and Van Rensbergen J (2000) Development of cloud, snow, and shadow masking algorithms for VEGETATION imagery. In IGARSS 2000. IEEE 2000 Int. Geoscience and Remote Sensing Symp. Taking the Pulse of the Planet: The Role of Remote Sensing in Managing the Environment. Proceedings (Cat. No.00CH37120), Belgirate, 303-306 (doi: 10.1109/IGARSS.2000.861719)
Lliboutry L (1965) Traité de glaciologie. Tome II: Glaciers, variations du climat, sols gelés. Masson et. Paris

Maisongrande P, Duchemin B and Dedieu G (2004) VEGETATION/ SPOT: an operational mission for the Earth monitoring; presentation of new standard products. Int. J. Remote Sens., 25(1), 9-14 (doi: 10.1080/0143116031000115265)

Marzeion B, Hofer M, Jarosch AH, Kaser G and Mölg T (2012) A minimal model for reconstructing interannual mass balance variability of glaciers in the European Alps. Cryosphere, 6(1), 71-84 (doi: 10.5194/tc-6-71-2012)

Marzeion B, Leclercq PW, Cogley JG and Jarosch AH (2015) Brief communication: global glacier mass loss reconstructions during the 20th century are consistent. Cryosph. Discuss., 9(4), 38073820 (doi: 10.5194/tcd-9-3807-2015)

Mernild SH and 5 others (2013) Identification of snow ablation rate, ELA, AAR and net mass balance using transient snowline variations on two arctic glaciers. J. Glaciol., 59(216), 649-659 (doi: 10.3189/2013JoG12J221)

Michaelsen J (1987) Cross-validation in statistical climate forecast models. J. Clim. Appl. Meteorol., 26, 1589-1600 (doi: 10.1175/1520-0450(1987)026<1589:CVISCF > 2.0.CO;2)

Ohmura A (2011) Observed mass balance of Mountain Glaciers and Greenland Ice Sheet in the 20th century and the present trends. Surv. Geophys., 32(4-5), 537-554 (doi: 10.1007/s10712-0119124-4)

Ostrem G (1973) The transient snowline and glacier mass balance in southern British Columbia and Alberta, Canada. Geogr. Ann., 55A(2), 93-106

Østrem G and Brugman M (1991) Glacier mass-balance measurements: a manual for field and office work. NHRI Science Report. Saskatoon, Canada

Paul F, Frey H and Le Bris R (2011) A new glacier inventory for the European Alps from Landsat TM scenes of 2003 : challenges and results. Ann. Glaciol., 52(59), 144-152

Pelto M (2011) Utility of late summer transient snowline migration rate on Taku Glacier, Alaska. Cryosphere, 5(4), 1127-1133 (doi: 10.5194/tc-5-1127-2011)

Pelto M and Brown C (2012) Mass balance loss of Mount Baker, Washington glaciers 1990-2010. Hydrol. Process., 26(17), 2601-2607 (doi: 10.1002/hyp.9453)

Pfeffer WT and 18 others (2014) The Randolph Glacier Inventory: a globally complete inventory of glaciers. J. Glaciol., 60(221), 537552 (doi: 10.3189/2014JoG13J176)

Rabatel A, Dedieu JP and Vincent C (2005) Using remote-sensing data to determine equilibrium-line altitude and mass-balance time series: validation on three French glaciers, 1994-2002. J. Glaciol., 51(175), 539-546 (doi: 10.3189/172756505 781829106)

Rabatel A and 7 others (2012) Can the snowline be used as an indicator of the equilibrium line and mass balance for glaciers in the outer tropics? J. Glaciol., 58(212), 1327-1336 (doi: 10.3189/ 2012JoG12J027)

Rabatel A, Letréguilly A, Dedieu JP and Eckert N (2013) Changes in glacier equilibrium-line altitude in the western Alps from 1984 to 2010: evaluation by remote sensing and modeling of the morpho-topographic and climate controls. Cryosphere, 7(5), 1455-1471 (doi: 10.5194/tc-7-1455-2013)

Rabus B, Eineder M, Roth A and Bamler R (2003) The shuttle radar topography mission - a new class of digital elevation models acquired by spaceborne radar. ISPRS J. Photogramm. Remote Sens., 57(4), 241-262 (doi: 10.1016/S0924-2716(02)00124-7)

Radić $V$ and 5 others (2014) Regional and global projections of twenty-first century glacier mass changes in response to climate scenarios from global climate models. Clim. Dyn., 42(1-2), 37-58 (doi: 10.1007/s00382-013-1719-7)

Rahman H and Dedieu G (1994) SMAC: a simplified method for the atmospheric correction of satellite measurements in the solar spectrum. Int. J. Remote Sens., 15(1), 123-143 (doi: 10.1080/ 01431169408954055)

Salomonson VV and Appel I (2004) Estimating fractional snow cover from MODIS using the normalized difference snow index. 
Remote Sens. Environ., 89(3), 351-360 (doi: 10.1016/j.rse. 2003.10.016)

Shea JM, Menounos B, Dan Moore R and Tennant C (2012) Regional estimates of glacier mass change from MODIS-derived equilibrium line altitudes. Cryosph. Discuss., 6(5), 3757-3780 (doi: 10.5194/tcd-6-3757-2012)

Shea JM, Menounos B, Moore RD and Tennant C (2013) The Cryosphere An approach to derive regional snow lines and glacier mass change from MODIS imagery, western North America. Cryosphere, 7, 667-680 (doi: 10.5194/tc-7-667-2013)

Sirguey P, Mathieu R and Arnaud Y (2009) Subpixel monitoring of the seasonal snow cover with MODIS at $250 \mathrm{~m}$ spatial resolution in the Southern Alps of New Zealand: methodology and accuracy assessment. Remote Sens. Environ., 113(1), 160-181 (doi: 10.1016/j.rse.2008.09.008)

Soruco A and 9 others (2009) Mass balance of Glaciar Zongo, Bolivia, between 1956 and 2006, using glaciological, hydrological and geodetic methods. Ann. Glaciol., 50(50), 1-8

Sylvander S, Henry P, Bastien-Thiry C, Meunier F and Fuster D (2000) Sylvander, S. Saint G. Ed C-T\& J-I ed. In Proceedings of the VEGETATION 2000 conference, Belgirate-Italy, 33-44

Tarpley JD, Schneider SR and Money RL (1984) Global vegetation indices from the NOAA-7 Meteorological Satellite. J. Clim. Appl. Meteorol., 23(3), 491-494 (doi: 10.1175/1520-0450 (1984)023<0491:GVIFTN > 2.0.CO;2)

Thibert E, Blanc R, Vincent C and Eckert N (2008) Glaciological and volumetric mass balance measurements: glaciological and volumetric mass balance measurements: error analysis over 51 years for the Sarennes glacier, French Alps. J. Glaciol., 54(186), 1-36 (doi: 10.3189/002214308785837093)

Thibert E, Eckert N and Vincent C (2013) Climatic drivers of seasonal glacier mass balances: an analysis of 6 decades at Glacier de
Sarennes (French Alps). Cryosphere, 7, 47-66 (doi: 10.5194/tc7-47-2013)

Vincent $C$ and 5 others (2004) Ice ablation as evidence of climate change in the Alps over the 20th century. J. Geophys. Res., 109 (doi: 10.1029/2003JD003857)

Werner M (2001) Shuttle radar topography mission (SRTM), mission overview. J. Telecom., 55, 75-79

WGMS (2008) Fluctuations of Glaciers 2000-2005, Volume IX. Zurich, Switzerland

WGMS (2012) Fluctuations of Glaciers 2005-2010. Zurich, Switzerland (doi: 10.5904/wgms-fog-2012-11)

WGMS (2013) Glacier Mass Balance Bulletin No. 12 (2010-2011). Zurich, Switzerland (doi: 10.5904/wgms-fog-2013-11)

Wilks DS (2011) Statistical methods in the atmospheric sciences, 3rd edn. (International Geophysics Series 100) Academic Press, Oxford

Willis MJ, Herried BG, Bevis MG and Bell RE (2015) Recharge of a subglacial lake by surface meltwater in northeast Greenland. Nature, 518(7538), 223-227 (doi: 10.1038/nature14116)

Xiao X, Shen Z and Qin X (2001) Assessing the potential of VEGETATION sensor data for mapping snow and ice cover: a normalized difference snow and ice index. Int. J. Remote Sens., 22(13), 2479-2487 (doi: 10.1080/01431160119766)

Zemp M and 16 others (2013) Reanalysing glacier mass balance measurement series. Cryosphere, 7(4), 1227-1245 (doi: 10.5194/tc-7-1227-2013)

Zemp M and 38 others (2015) Historically unprecedented global glacier decline in the early 21 st century. J. Glaciol., 61(228), 745-762 (doi: 10.3189/2015JoG15J017)

Zhu Z and Woodcock CE (2012) Object-based cloud and cloud shadow detection in Landsat imagery. Remote Sens. Environ., 118, 83-94 (doi: 10.1016/j.rse.2011.10.028) 